\title{
Rapid Diagnosis of Lower Respiratory Infection using Nanopore-based Clinical Metagenomics
}

Themoula Charalampous $^{1 *}$, Hollian Richardson ${ }^{1 *}$, Gemma L. Kay ${ }^{1 *}$, Rossella Baldan $^{1,2}$, Christopher Jeanes ${ }^{3}$, Duncan Rae ${ }^{3}$, Sara Grundy ${ }^{3}$, Daniel J. Turner ${ }^{4}$, John Wain ${ }^{1,5}$, Richard M. Leggett ${ }^{6}$, David M. Livermore ${ }^{1,7}$ and Justin O'Grady ${ }^{1,5^{\wedge}}$

${ }^{1}$ Bob Champion Research and Educational Building, University of East Anglia, Norwich Research Park, Colney Ln, Norwich, UK, NR4 7UQ.

${ }^{2}$ CIDR, King's College London, St Thomas' Hospital, Westminster Bridge Road, London, UK, SE1 7EH.

${ }^{3}$ Microbiology Department, Norwich and Norfolk University Hospital, Conley Ln, Norwich, UK, NR4 7GJ

${ }^{4}$ Oxford Nanopore Technologies, Gosling Building, Oxford Science Park, Edmund Halley Rd, Oxford, UK, OX4 4DQ

${ }^{5}$ Quadram Institute Bioscience, Norwich Research Park, Colney Ln, Norwich, UK, NR4 7UA

${ }^{6}$ Earlham Institute, Norwich Research Park, Conley Ln, Norwich, UK, NR4 7UZ

${ }^{7}$ AMRHAI, Public Health England, 61 Colindale Ave, London, NW9 5EQ.

${ }^{\wedge}$ Correspondence to justin.ogrady@quadram.ac.uk

*These authors contributed equally to this work: TC, HR, GLK 


\begin{abstract}
Lower respiratory infections (LRIs) accounted for three million deaths worldwide in 2016, the leading infectious cause of mortality. The "gold standard" for investigation of bacterial LRIs is culture, which has poor sensitivity and is too slow to guide early antibiotic therapy. Metagenomic sequencing potentially could replace culture, providing rapid, sensitive and comprehensive results. We developed a metagenomics pipeline for the investigation of bacterial LRIs using saponin-based host DNA depletion combined with rapid nanopore sequencing. The first iteration of the pipeline was tested on respiratory samples from 40 patients. It was then refined to reduce turnaround and increase sensitivity, before testing a further 41 samples. The refined method was $96.6 \%$ concordant with culture for detection of pathogens and could accurately detect resistance genes with a turnaround time of six hours. This study demonstrates that nanopore metagenomics can rapidly and accurately characterise bacterial LRIs when combined with efficient human DNA depletion.
\end{abstract}


Lower respiratory infections (LRIs) are the third most common cause of death globally and are the leading infectious cause, accounting for three million deaths worldwide in 2016 (http://www.who.int/news-room/fact-sheets/detail/the-top-10-causes-of-death). They can be subdivided into chest infection, community-acquired pneumonia (CAP), hospital-acquired pneumonia (HAP), bronchitis and bronchiolitis (https://www.nice.org.uk/guidance/cg191). Morbidity and mortality rates vary dependent on infection site, pathogen and host factors. In the UK, CAP accounts for approx. 29,000 deaths per annum and it is estimated that HAP accounts for approx. 36,000 deaths in the US per annum ${ }^{1}$. The most common bacterial agents of LRIs are Streptococcus pneumoniae and Haemophilus influenzae for CAP and Staphylococcus aureus, Enterobacteriaceae and Pseudomonas aeruginosa for HAP ${ }^{2-6}$. However, a wide range of pathogens, including viruses, can cause these infections, meaning that microbial diagnosis and treatment are challenging.

Every year in the UK NHS treat 16 million people with antibiotics for respiratory tract infections (https://www.nice.org.uk/guidance/cg191/documents/pneumonia-final-scope2). Initial treatment for severe LRIs, particularly HAP, often involves empirical broad-spectrum antibiotics. Guidelines recommend that such therapy should be refined or stopped after two to three days, once microbiology results become available ${ }^{7-9}$, but this is often not done, if the patient is responding well or the laboratory has failed to identify a pathogen. Such extensive 'blind' use of broad-spectrum antibiotics is wasteful and constitutes poor stewardship, given that many patients are infected with a virus or a susceptible pathogen. Antimicrobial over-treatment leads to disruption of the gut flora, promoting the risk of overgrowth by resistant bacteria and of Clostridium difficile ${ }^{10,11}$.

There is an urgent need for rapid microbiological diagnostics to ensure swift tailored treatment and to reduce prolonged broad-spectrum antibiotic therapy. "Gold standard" culture and susceptibility testing is not fit for purpose in this regard, owing to slow turnaround times (48-72 hours) and low clinical sensitivity ${ }^{1,2,7,12}$. Molecular methods have the potential 
to overcome this limitations, as highlighted by the Chief Medical Officer and O'Neill reports (2016), identifing pathogens and their antibiotic resistance profiles within a few hours, thereby allowing early therapeutic refinement, and supporting effective antibiotic stewardship 13, 14. However, molecular methods present their own challenges. Nucleic acid amplification tests (including PCR) are rapid and highly specific/sensitive, but uncommon agents and antibiotic resistances cannot readily be sough, given the limits on multiplexing ${ }^{8,15,16}{ }^{17}$. There is also a constant need to update these PCR-based methods to include emerging resistance genes and mutations ${ }^{9,18,19}$.

Metagenomic sequencing based approaches, which make no presumptions about the organisms and resistance genes that may be present, have the potential to overcome the shortcomings of both culture and PCR, by combining speed with comprehensiveness ${ }^{20}$. Nanopore sequencing (Oxford Nanopore Technologies, ONT) has particular potential for rapid diagnostic applications, with the advantage of real-time data acquisition and analysis 21,22 as compared with other NGS platforms (e.g. Illumina) where sequencing can take up to 48 hrs before analysis can begin ${ }^{23}$. Nanopore sequencing has previously been used to identify viral and bacterial pathogens from clinical samples using targeted approaches and in proof-of-concept studies using samples with high pathogen loads (e.g. urinary tract infection) $22,24,25$. Respiratory specimens present a greater challenge, owing to the variable pathogen load, the presence of commensal respiratory tract flora, and the high ratio of host:pathogen nucleic acids present (up to $10^{5: 1}$ in sputum).

It is possible to apply rapid metagenomics to respiratory samples, as demonstrated by Pendleton et al. (2017), who used nanopore sequencing, without host cell depletion, to samples from two bacterial pneumonia patients. The vast majority of reads, however, were of human origin, with only one and two nanopore reads aligned to the infecting pathogens, $P$. aeruginosa and $S$. aureus, respectively ${ }^{26}$. It seems likely that their method could be improved by depletion of host DNA but, although commercial kits and published methods 
are available for this purpose ${ }^{27,28}$, they do not perform well in complex respiratory samples and improved methods are required.

Accordingly, we developed and optimised a state-of-the-art nanopore-sequencing based clinical metagenomics pipeline for the investigation of bacterial LRIs capable of removing up to $99.99 \%$ host nucleic acid from clinical respiratory samples, enabling pathogen and antibiotic resistance gene identification within six hours.

\section{RESULTS}

\section{Pilot method testing}

The first 'Pilot' iteration of the metagenomics pipeline, the pilot method, was tested on respiratory samples from 40 patients with suspected bacterial LRI. Overall, this method was 91.2\% sensitive (95\% Cl; 75.2-97.7\%) and $83.3 \%$ specific $(95 \% \mathrm{Cl} ; 36.5-99.1 \%)$, not counting additional organisms in culture-positive samples as false positives (Table 1), and took approx. 8 hours to perform (Figure 1). Up to $99.9 \%$ or $\sim 10^{3}$ fold (average: $10^{3}$ fold; range: 32-1024 fold) of host DNA was removed using the saponin depletion. Pathogens were identified in real-time using ONT's What's In My Pot? (WIMP) pipeline. Additional pathogenic bacteria were detected in 6/40 samples: S. pneumoniae was detected in P20; Moraxella catarrhalis in P8; Escherichia coli in P14; H. influenzae in P22 and P30; Klebsiella pneumoniae and M. catarrhalis in P29 (Supplementary Table 1).

Organisms reported by routine microbiology were not detected in $3 / 40$ samples by the Pilot method. Two of these cases were mixed infections where one organism was missed by the Pilot method - specifically, S. pneumoniae and $H$. influenzae were not detected in P3 and P37 respectively - and S. aureus was not detected in P34. 


\section{Optimisation experiments}

Efforts were made to reduce major errors ( $8.8 \%$ false negative rate) by improving bacterial cell lysis, thereby improving assay performance. We also sought to reduce the sample-toresult turnaround time.

Improving bacterial cell lysis

A sample pre-treatment step was introduced, involving either bead-beating or an enzyme cocktail, to increase the lysis of difficult-to-lyse organisms. Two culture-positive sputa were used for optimisation experiments, one containing S. aureus (Gram-positive) and one containing $P$. aeruginosa (Gram-negative). Neither pre-treatment affected the yield of $P$. aeruginosa DNA, but the enzyme cocktail increased the amount of $S$. aureus DNA detected by approx. 4-fold and bead-beating achieved a 20 -fold increase compared with the pilot method, as determined by qPCR (Supplementary Table 2a). Accordingly, bead-beating was introduced as a standard pre-treatment in the Optimised method.

\section{Reducing turnaround time}

Prior to optimisation, the host DNA depletion method took approx. $1.5 \mathrm{hrs}$. Removal of the second DNase treatment and reducing the number of washes shortened this to $50 \mathrm{~min}$ without affecting the degree of human DNA depletion compared to the pilot method (average: $>10^{3}$ fold; ) (Supplementary Table $2 a$ ). Time could also be saved by reducing the library preparation PCR extension time from six to four minutes. Comparison of the microbial community profile after sequencing showed no difference in the top three most abundant species and only a small reduction in average fragment length $(<400 \mathrm{bp})$ between libraries produced with four and six minute extension times (Supplementary Table 2b). This enabled MinION library preparation to be completed within two hours and a half (reduced from 3.5 hours), giving an overall turnaround time of under four hours prior to DNA sequencing. 


\section{Limit of detection}

The limit of detection (LoD) of the method was determined using an uninfected 'normal respiratory flora' (NRF) sputum sample spiked with serial ten-fold dilutions of $S$. aureus and E. coli cultures at known cell densities. The LoD was defined as the fewest cells required for the identification of the infecting 'pathogen' using the analysis pipeline as follows: $\geq 1 \%$ microbial reads identified using WIMP and an alignment score $\geq 20$. The LoD was determined to be $10,000\left(10^{4}\right)$ cells for both E. coli and S. aureus (Supplementary Table 3).

\section{Mock community detection}

The Optimised method was tested in triplicate on a panel of common respiratory pathogens spiked into NRF sputum ( $\sim 10^{8} \mathrm{cfu} / \mathrm{ml}$ per pathogen) to determine whether the saponin human DNA depletion method led to inadvertent loss of any bacterial DNA. We observed no bacterial DNA loss (average $\Delta \mathrm{Cq}<1$ ) for any organisms (E. coli, $H$. influenzae, $K$. pneumoniae, $P$. aeruginosa, S. aureus and S. maltophilia) tested except S. pneumoniae where there was a 5.7-fold loss, (average $\Delta \mathrm{Cq} 2.52$ ) between depleted and undepleted samples (Supplementary Table 4).

\section{Optimised method evaluation}

The optimised method was then tested on 41 respiratory samples from patients with suspected bacterial LRIs. A maximum of $10^{4}$ fold depletion of human DNA (average $10^{3}$ fold; range 4.8-18,054 fold) was observed between depleted and undepleted samples (Table 2). The overall sensitivity of the refined method for the detection of respiratory pathogens was $96.6 \%(95 \% \mathrm{Cl}, 80.4-99.8 \%)$, specificity was $41.7 \%$ (95\% Cl, $16.5-71.4 \%)$, again not counting additional organisms in culture-positive samples as false positives (Table 3 ). The turnaround time from sample to result was approx. 6 hours (including 2 hours MinION sequencing) (Supplementary Table 5). 
The pathogenic organism reported by routine microbiology was detected together with an additional pathogen (not reported by culture) in eight samples: $K$. pneumoniae in S5, $P$. aeruginosa in S7, M. catarrhalis in S14 and S39, S. aureus in S29 and S. pneumoniae in S8 and S15 (Table 2). Up to two potentially pathogenic bacteria were also observed in seven samples reported as NRF/no significant growth (NSG) by routine microbiology, (S10, 11, 12, 21, 28, 31 and 32). H. influenzae and S. pneumoniae in S10 and S21; S. pneumoniae in S11 and S28; M. catarrhalis and H. influenzae in S12; H. influenzae in S31 and E. coli in S32. Only one pathogenic organism reported by routine microbiology was not detected using the Optimised method. Specifically, $\$ 9$ was reported as a mixed infection with $P$. aeruginosa and E. coli whereas only E. coli was detected by metagenomics. There were two other mixed infections reported by routine microbiology, both involving $S$. aureus together with $H$. influenzae (S27 and S41), and both organisms were detected using the Optimised method.

\section{Antibiotic resistance analysis}

The collection of samples tested using the optimised method had low rates of antibiotic resistance, as determined by routine testing (Supplementary table 6). Across the 33 cultivated organisms, just 38 instances of resistance or intermediate resistance to tested antibiotics were recorded (Table 4), and some of these overlapped (e.g. two S. aureus were resistant to oxacillin, flucloxacillin and penicillin).

Of these 38, five could be discounted as resistance inherent in the cultured species (e.g. to penicillins in K. pneumoniae and co-amoxiclav in Serratia marcescens). Of the remaining 33, 14 could be explained by the resistance genes found (all resistance genes were detected using ONT's Antimicrobial Resistance Mapping Application - ARMA), including mecA found in both MRSA (S16 and S40), sul1 and dfrA12 or dfrA17 genes found in each of two cotrimoxazole resistant $E$. coli (S1 and S9), aac(3')-Ila (and I/c) in a tobramycin-resistant E. coli (S9) and bla TEM variants found in each of two amoxicillin-resistant E. coli (S1 and S35) and amoxicillin-resistant $H$. influenzae (S18 and S36). A caveat apropos blatem is that ARMA 
mostly flagged blaTEM-4 when blaTEM-1 was considerably more likely given its vastly greater prevalence and the fact that the isolates remained susceptible to oxyimino- cephalosporins, which are substrates for TEM-4. Another $6 / 33$ cases concerned non-susceptibility to penicillin/ $\beta$-lactamase inhibitor combinations in isolates where bla TEM or (K. oxytoca) blaoxy was found; resistance here may be associated with these enzymes, but depends on their level of expression, which was not investigated (or measurable) by the present pipeline. Next, 2/33 instances concerned a specimen where $P$. aeruginosa (S37) was cultured and found resistant to ceftazidime and piperacillin/tazobactam: blaTEM-4 was found and could explain this phenotype but is unlikely in $P$. aeruginosa, where $\beta$-lactam resistance mostly reflects up-regulation of chromosomal ampC or efflux.

This leaves $11 / 33$ instances where observed resistance was not explained by the genes found. Two of these were amoxicillin-resistant M. catarrhalis (S8 and S26), where genes for the likely BRO $\beta$-lactamases are absent from the ARMA databases. Another six, variously including ampicillin and co-trimoxazole resistance in $H$. influenzae (S7, S18, S36, S39 and S41) and resistances to trimethoprim, ciprofloxacin and fusidic acid in S. aureus (S16) were phenotypes where modification of chromosomal genes is the likely source of resistance, and the relevant sequence data is not analysed by ARMA. Last, there were three instances one $S$. aureus resistant to gentamicin (S16) and a K. pneumoniae (S2) resistant to both coamoxiclav and piperacillin/tazobactam but lacking any acquired $\beta$-lactamase, where we cannot explain the failure of sequencing to identify a likely mechanism.

Looked at another way, sequencing identified 184 resistance genes across the 41 specimens, based on multiple inclusion when ARMA identified multiple variants of e.g. bla TEM in a specimen. Many of these genes are likely to have originated from the normal flora, as evidenced by the fact that tet(M) was found in 8/12 NRF/NSG specimens as was blaTEM-4, whilst mefA and mel were each found in 9/12 such samples. Other genes, including sul1, dfr 
determinants and $\operatorname{mec} A$ were, however, only found in association with cultivation of an organism with the corresponding resistance. Endogenous resistance genes of cultivated species were widely seen, such as blaoxA-50, catB7 and aph(3')-Ilb in $P$. aeruginosa (S3, S29, S30 and S37) and aac(6')-Ic in S. marcescens (S4 and S13).

The specificity and sensitivity of the developed method for resistance gene detection was not determined as this would have required isolating and sequencing all bacteria (pathogens and commensals) present in the sputum samples, which was beyond the scope of the study.

\section{Reference-based genome assembly}

Two samples containing antibiotic resistant bacteria were chosen as examples to generate reference-based genome assemblies directly from the metagenomic data. Assemblies were generated for an MRSA (S16) and an E. coli resistant to amoxicillin, co-amoxiclav and cotrimoxazole (S1). The results were compared with those for undepleted controls after two and 48 hours of sequencing. Within the first two hours of sequencing the human DNA depleted MRSA sample had $64.7 x$ genome coverage with an assembly of 64 contigs (longest contig $=1360276$ and N50=106kbp, data not shown). Genome coverage increased to $232.5 \mathrm{x}$ after $48 \mathrm{hrs}$ of sequencing, with a final assembly consisting of 22 contigs (longest contig $=481 \mathrm{kbp}$ and $\mathrm{N} 50=402 \mathrm{kbp})$. After $48 \mathrm{hrs}$ of sequencing both the depleted and undepleted MRSA samples had sufficient coverage to enable assembly, though coverage was much greater for the depleted sample (232.5x) than the undepleted (18.5x) with a final assembly of 34 contigs (longest contig $=416 \mathrm{kbp}$ and N50=178kbp) (Figure 2a) At $2 \mathrm{hrs}$ of sequencing the undepleted MRSA sampe had an assembly of 216 contigs (longest contig = $32 \mathrm{kbp}$ and $\mathrm{N} 50=7 \mathrm{kbp}$, data not shown).

For the sample positive for resistant $E$. coli there was $21 \mathrm{x}$ genome coverage within two hours, with an assembly of 83 contigs (longest contig $=437 \mathrm{kbp}$ and N50 $=164 \mathrm{kbp}$, data not shown). Genome coverage increased to $165 \mathrm{x}$ after $48 \mathrm{hrs}$ with the final $E$. coli assembly 
having 78 contigs (longest contig $=473 \mathrm{kbp}$ and $\mathrm{N50}=177 \mathrm{kbp}$ ). The undepleted sample data only produced $0.3 \mathrm{x}$ coverage after $2 \mathrm{hrs}$, which increased to $1.2 \mathrm{x}$ genome coverage after 48 hrs sequencing (Figure $2 b$ ).

\section{Time-point analysis}

Using the same sample set as for genome assembly, data from the first two hours of sequencing were compared over time for depleted samples and undepleted controls. Within 5 min of sequencing the depleted MRSA sample (S16) had 3x genome coverage compared with the undepleted control (S16-undepleted) at 0.6x coverage (Figure $2 \mathrm{c}$ ). The mecA gene was not detected in the undepleted sample after 5 min whereas two mecA gene alignments were detected in the depleted sample by the same time point (Figure 2d).

The depleted E. coli sample (S1) had 1.74x genome coverage within 5 min of sequencing whereas the undepleted control (S1-undepleted) had $0.03 x$ (Figure 2e). This E. coli was resistant to amoxicillin (blaTEM gene), co-amoxiclav (possibly owing to bla TEM if strongly expressed) and co-trimoxazole (sul1 and dfrA17 genes). The blaтЕм and dfrA17 genes were not detected in the undepleted sample within two hours of sequencing and only one alignment was detected for sul1. Conversely, all three resistance genes were detected within 20 min of sequencing in the depleted sample and, after two hours, 57 bla TEM, 38 sulf1 and 22 dfrA17 alignments were detected (Figure 2f).

\section{Cost}

The running cost of the optimised pipeline developed in this study was approximately $\$ 130$ per sample when run in batches of six per flowcell ( $\$ 546$ for singleplex runs) (Supplementary Table 7). 


\section{Discussion}

Current culture-based diagnostics and susceptibility testing, though used for 70 years ${ }^{29}$, have serious limitations as guides for the appropriate clinical management of acute serious infection. This is mainly due to slow sample-to-result turnaround. Rapid, accurate diagnostics are urgently required, so that patients can be prescribed appropriate antibiotics as quickly as possible, potentially improving both outcomes and antimicrobial stewardship. We developed and tested a novel nanopore sequencing-based clinical metagenomics pipeline for the microbiological investigation (pathogen and antibiotic resistance gene identification) of bacterial LRIs within 6h of clinical diagnosis (assuming the sample is tested immediately).

We began by developing an efficient method for the removal of host DNA from sputum, bronchoalveolar lavage (BAL) and endotracheal aspirates (ETAs). This saponin-based differential lysis method resulted in $\sim 10^{3}$-fold host DNA depletion without any significant bacterial loss. This high efficiency depends upon the high concentrations of saponin and nuclease buffer salt used. A very high salt buffer $(5.5 \mathrm{M} \mathrm{NaCl})$ was found to be optimal for nuclease (HL-SAN) digestion of DNA, even though this was far beyond the manufacturer's recommended range for optimum activity. This, combined with a final saponin concentration of $2.2-2.5 \%$, which is higher than used in other saponin based depletion methods ${ }^{19}$, resulted in efficient leukocyte lysis and efficient human DNA depletion. It should be noted that, the same method depletes approx. $10^{5}$-fold human DNA on average from less inhibitory sample types such as blood and tissue (data not shown). Forty LRI samples were sequenced using the initial Pilot method, which was $91.2 \%$ sensitive and $83.3 \%$ specific for the detection of respiratory pathogens compared with "gold standard" culture.

The Pilot method was then optimised, by shortening the depletion protocol, introducing bead-beating for improved organism lysis, and reducing the library preparation time by shortening the PCR extension time. The Optimised method was $96.6 \%$ sensitive with a 
turnaround time of six hours. Only one pathogen (1/41) detected by culture was missed (false-negative major error) using the Optimised method (vs. 3/40 using Pilot method); specifically, a $P$. aeruginosa, which was found by culture in a mixed infection with $E$. coli. Possible explanations for missing this pathogen are (i) PCR competition/bias leading to preferential amplification of DNA from the more abundant pathogen or (ii) loss of pseudomonal DNA during host depletion, caused by damaged but viable cells sensitive to saponin lysis. Nevertheless, the mock community experiments demonstrated that common respiratory pathogens including $P$. aeruginosa were not effected by saponin depletion, the sole notable exception being S. pneumoniae. Under stress, S. pneumoniae is prone to autolysis through the activation of a pneumolysin gene, and this may occur to a portion of the bacteria during the host DNA depletion process ${ }^{30}$ (but may also have been caused by autolysis of S. pneumoniae when growing to stationary phase for mock community experiments). S. pneumoniae was correctly identified in five of six patients found by culture to be infected with S. pneumoniae, but it may have been underrepresented in these samples. The time from sample collection to bacterial DNA extraction may be a critical factor for the accurate detection of S. pneumoniae.

The specificity of the Optimised method was significantly lower than the Pilot method $(41.6 \%$ vs $83.3 \%$ ). This is likely to be related to the increased sensitivity of the Optimised method (96.5\% vs $91.2 \%)$. Metagenomic detection of additional pathogens compared to culture was expected as the clinical laboratory routinely dilutes the sample (1/1000) before plating and we used a larger sample volume $(400 \mu \mathrm{l}$ vs $10 \mu \mathrm{l})$. Most (10/17) of the additional organisms detected were potential known pathogens that can also be carried as commensals in the respiratory tract, notably including S. pneumoniae and $H$. influenzae ${ }^{31-33}$. Hence, it is likely that the additional pathogens not detected by culture were present in the samples and that culture either failed to detect them or did not report them as significant. However, some of the additional detection observed might be due to bioinformatic misclassification, as $k$-mer based read classification can be unreliable at the species level, particularly where species in 
a genus are highly related or share genes. This is particularly important in samples containing high numbers of commensal Streptococci/Haemophilus where a proportion of commensal reads can be misclassified as pathogen reads ${ }^{34,35}$.

Cut-offs, in terms of number of bacteria per $\mathrm{ml}$ of body fluid, are applied in clinical microbiology laboratories for some infections including those of the urinary and respiratory tracts. The same approach is required for metagenomics. The clinical cut-off used for respiratory samples is typically $10^{4}$ pathogens per $\mathrm{ml}$ of sample (range $10^{3}-10^{5}$ per $\mathrm{ml}$ dependent on sample type - achieved by sample dilution) ${ }^{36}$. We routinely applied cut-offs at $1 \%$ of classified reads, with a WIMP alignment score $\geq 20$. We chose these cut-offs to: censor reads arising from pipeline contaminants; remove barcode leakage between samples on multiplexed runs (ONT's Flongle (https://nanoporetech.com/products/comparison), an adapter for single use flowcells designed for diagnostic applications, should overcome this issue) and; remove low quality WIMP alignments, which result in misclassified reads. Results from our LoD experiments for the Optimised pipeline $\left(10^{4} \mathrm{cells} / \mathrm{ml}\right)$ are within the range of culture-based clinical cut-off. More precise methods for identifying pathogen species in clinical metagenomic data are urgently required.

To maximise the impact on patient management, identification of clinically relevant antibiotic resistance genes as well as the infecting pathogen/s is necessary. In this regard the present pipeline has potential but requires refinement. Both MRSA cases were identified by the presence of $m e c A$, with no false positives for this gene. Co-trimoxazole resistance in Enterobacteriaceae was accurately identified with detection of sul and dfr genes and these were not found in $H$. influenzae, for which resistance is largely mutational ${ }^{37,38}$. However, genes such as tet(M), mel, mefA and bla TEM were found in 8/12 samples where no pathogen was grown, suggesting presence in the normal or colonising respiratory flora. To overcome this issue, it would be necessary to associate resistance genes to particular organisms. This can be done by examining flanking sequences ${ }^{39-42}$ in the c. $3 \mathrm{~kb}$ nanopore reads in cases 
where a gene is chromosomally inserted, as is usual for transposon borne tet(M) and mefA in streptococci ${ }^{43-45}$ (Supplementary Figure 1), including S. pneumoniae, but will not determine the source of plasmid-borne resistance genes. Real-time consessus calling for the detection of mutational resistance and chromosomal resistance gene source determination functionality would significantly improve the accuracy of the ARMA output.

An additional advantage of implementing clinical metagenomics (compared to other rapid tests e.g. PCR) is the impact it could have beyond clinical diagnosis. To illustrate this potential, the data generated after $48 \mathrm{hrs}$ of sequencing was used to perform reference based pathogen genome assemblies, identifying bacteria beyond species level ${ }^{17}$. Such information is equivalent to reference laboratory typing which is, in the UK, carried out by whole genome sequencing of isolates. The quality of the metagenomic data generated by the method reported here would allow investigations of the emergence and patient-to-patient spread of pathogens and antimicrobial resistance directly from clinical samples in real-time 46, 47. Currently it would be necessary to run "reference" culture alongside PCR based approaches, otherwise the link to phenotypes would be lost - clinical metagenomics, on the other hand, has the potential to replace routine culture, allowing it to be reserved for more unusual pathogens/resistances.

In conclusion, we report the first rapid clinical metagenomics pipeline for the microbiological investigation of bacterial LRIs. The method provides accurate pathogen and antibiotic resistance gene identification within six hours. With additional sequencing time (up to 48 hrs), it provides sufficient data for public health and infection control applications. The pipeline is currently being evaluated in a clinical trial (INHALE http://www.ucl.ac.uk/news/news-articles/1115/181115-molecular-diagnosis-pneumonia) on the rapid diagnosis of hospital-acquired and ventilator-associated pneumonia. 


\section{Methods}

\section{Ethics}

This study used excess respiratory samples, after routine microbiology diagnostic tests had been performed, from patients with suspected LRIs such as persistent (productive) cough, bronchiectasis, CAP/HAP, cystic fibrosis and exacerbation of chronic obstructive pulmonary disease (COPD, emphysema/chronic bronchitis). Ethical approval was not required as the samples were used for method development, and no patient identifiable information was collected. The only data collected were routine microbiology results, which detailed the pathogen(s) identified and their antibiotic susceptibility profiles.

\section{Routine clinical microbiological investigation}

Respiratory samples including sputum, endotracheal secretions and ETAs were treated with sputasol (Oxoid-SR0233) in a 1:1 ratio before being incubated for a minimum of 15 min at 37 ${ }^{\circ} \mathrm{C}$. Sputasol-treated respiratory samples $(10 \mu \mathrm{l})$ were inoculated into $5 \mathrm{ml}$ of sterile water and mixed. Following this, $10 \mu \mathrm{l}$ of sample was streaked onto blood, chocolate and cysteine lactose electrolyte deficient (CLED) agar. BAL samples, they were not treated with sputasol; instead they were centrifuged to concentrate bacterial cells for a minimum of $10 \mathrm{~min}$ at 3000 rpm. BALs did not undergo further dilution and were streaked directly onto the agar plate. Depending on clinical details and the source of the specimen, other agar plates (including sabouraud, mannitol salt and Burkholderia cepacia selective agar) were additionally used.

All inoculated agar plates were incubated at $37^{\circ} \mathrm{C}$ overnight and then examined for growth with the potential for re-incubation up to 48 hours. If any significant organism was grown then antibiotic susceptibility testing by agar diffusion using EUCAST methodology was performed. The laboratory's Standard Operating Procedure is based on the Public Health England UK Standards for Microbiology Investigations B 57: Investigation of bronchoalveolar lavage, sputum and associated specimens ${ }^{36}$. 


\section{Sample collection and storage}

The excess respiratory samples (sputa, ETA, BAL) were collected after culture and susceptibility testing at Norfolk and Norwich University Hospitals (NNUH) Microbiology Department (described above) and stored at $4{ }^{\circ} \mathrm{C}$ prior to testing. They were indicated by clinical microbiology to contain bacterial pathogen(s), NRF or to have yielded NSG. Forty samples ( $n=34$ positive and $n=6$ NRF samples, comprising 34 sputa, four BALs and two ETAs) were used to test the first 'Pilot" iteration of the diagnostic pipeline and another 41 ( $\mathrm{n}=29$ suspected LRI, $\mathrm{n}=9$ NRF and $\mathrm{n}=3$ NSG samples, comprising 38 sputa, one BAL and two ETAs) to test the Optimised pipeline.

\section{First iteration of the diagnostic pipeline (Pilot method): Host DNA Depletion}

Respiratory samples $(400 \mu \mathrm{l})$ were centrifuged at $8000 \mathrm{xg}$ for $5 \mathrm{~min}$, after which the supernatant was carefully removed and the pellet resuspended in $250 \mu$ l of PBS, any pellet $>50 \mu \mathrm{l}$ was diluted one in four and re-centrifuged. The saponin-based differential lysis method was modified from previously reported saponin methods ${ }^{48,49}$ : saponin (Tokyo Chemical Industry- S0019) was added to a final concentration of $2.5 \%$ (200 $\mu \mathrm{l}$ of $5 \%$ saponin), mixed well and incubated at room temperature (RT) for 10 min to promote host cell lysis. Following this incubation, $350 \mu \mathrm{l}$ of water was added and incubation was continued at $\mathrm{RT}$ for $30 \mathrm{~s}$, after which $12 \mu \mathrm{l}$ of $5 \mathrm{M} \mathrm{NaCl}$ was added to deliver an osmotic shock, lysing the damaged host cells. Samples were next centrifuged at $6000 \mathrm{xg}$ for $5 \mathrm{~min}$, with the supernatant removed and the pellet resuspended in $100 \mu$ l of PBS. HL-SAN buffer (5.5 M $\mathrm{NaCl}$ and $100 \mathrm{mM} \mathrm{MgCl}_{2}$ in nuclease-free water) was added $(100 \mu \mathrm{l})$ with $5 \mu \mathrm{l} \mathrm{HL-SAN}$ DNase (25,000 units, Articzymes - 70910-202) and incubated for $15 \mathrm{~min}$ at $37^{\circ} \mathrm{C}$ with shaking at 800 RPM for host DNA digestion. An additional $2 \mu$ of HL-SAN DNase was added to the sample, which next was incubated for a further $15 \mathrm{~min}$ at $37^{\circ} \mathrm{C}$ with shaking at 800 RPM. Finally, the host-DNA depleted samples were washed three times with decreasing volumes of PBS $(300 \mu \mathrm{l}, 150 \mu \mathrm{l}, 50 \mu \mathrm{l})$. After each wash, the sample was centrifuged at 6000 $\mathrm{xg}$ for $3 \mathrm{~min}$, the supernatant discarded and the pellet resuspended in PBS. 


\section{Pilot method: Bacterial Lysis and DNA Extraction}

After the final wash step of the host depletion, the pellet was resuspended in $380 \mu$ l of bacterial lysis buffer (Roche UK- 4659180001) and $20 \mu$ l proteinase K (>600mAu/ml) (Qiagen -19133) was added before incubation at $65^{\circ} \mathrm{C}$ for 10 min with shaking at $800 \mathrm{RPM}$ (on an Eppendorf Thermomixer). Nucleic acid was then extracted from samples using the Roche MagnaPure Compact DNA_bacteria_V3_2 protocol (MagNA pure compact NA isolation kit I, Roche UK- 03730964001) on a MagNA Pure Compact machine (Roche UK$03731146001)$

\section{Optimised method: Host DNA Depletion (Figure 1)}

The optimized method sought to improve and shorten some steps. Specifically, after the first 5 min centrifugation at $8000 \times \mathrm{g}$, up to $50 \mu \mathrm{l}$ of supernatent was left so as to not disturb the pellet (final saponin conc. 2.2-2.5\%). Instead of performing two rounds of host DNA digestion, the amount of HL-SAN DNase was increased up to $10 \mu \mathrm{l}$ and a single incubation of $15 \mathrm{~min}$ at $37^{\circ} \mathrm{C}$ was carried out with shaking at 800 RPM on an Eppendorf Thermomixer. Finally, the number of washes was reduced to two with increasing volumes of PBS $(800 \mu \mathrm{l}$ and $1 \mathrm{ml})$.

\section{Optimised method: Bacterial Lysis and DNA Extraction (Figure 1)}

After the final wash, the pellet was re-suspended in $500 \mu$ l of bacterial lysis buffer (Roche UK - 4659180001), transferred to a bead-beating tube (Lysis Matrix E, MP Biomedicals 116914050 ) and bead-beaten at maximum speed (50 oscillations per second) for 3 min in a Tissue Lyser bead-beater (Qiagen - 69980). This ensured the release of DNA from difficultto-lyse organisms (e.g. S. aureus). The sample was centrifuged at 20,000 xg for $1 \mathrm{~min}$ and $\sim 230 \mu \mathrm{l}$ of supernatant was transferred to a fresh Eppendorf tube. The volume was toppedup with $170 \mu \mathrm{l}$ of bacterial lysis buffer and $20 \mu \mathrm{l}$ of proteinase $\mathrm{K}(>600 \mathrm{mAu} / \mathrm{ml}$, Qiagen 19133) was added. Samples were then incubated at $65^{\circ} \mathrm{C}$ for 5 min with shaking at 800 RPM on an Eppendorf Thermomixer. DNA was extracted from samples using the Roche 
MagnaPure Compact DNA_bacteria_V3_2 protocol (MagNA pure compact NA isolation kit I, Roche UK - 03730964001) on a MagNA Pure Compact machine (Roche UK $03731146001)$.

\section{DNA quantification and quality control}

DNA quantification was performed using the high sensitivity dsDNA assay kit (Thermo Fisher - Q32851) on the Qubit 3.0 Fluorometer (Thermo Fisher - Q33226). DNA quality and fragment size (PCR products and MinION libraries) were assessed using the TapeStation 2200 (Agilent Technologies - G2964AA) automated electrophoresis platform with the Genomic ScreenTape (Agilent Technologies - 5067-5365) and a DNA ladder (200 to $>60,000$ bp, Agilent Technologies - 5067-5366).

\section{MinION Library Preparation and Sequencing}

MinION library preparation was performed according to the manufacturer's instructions for (i) the Rapid Low-Input by PCR Sequencing Kit (SQK-RLI001), (ii) the Rapid Low-Input Barcoding Kit (SQK-RLB001) or (iii) the Rapid PCR Barcoding Kit (SQK-RPB004) with minor alterations as follows. For single sample sequencing runs using the SQK-RLI001 kit, $10 \mathrm{ng}$ of the MagNA Pure-extracted DNA were used for the tagmentation/fragmentation reaction, where DNA was incubated at $30^{\circ} \mathrm{C}$ for $1 \mathrm{~min}$ and at $75^{\circ} \mathrm{C}$ for $1 \mathrm{~min}$. The PCR reaction was run as per the manufacturer's instructions; however, the number of PCR cycles was increased to 20. For multiplexed runs, SQK-RLB001 and SQK-RPB004 kits were used. A 1.2x AMPure XP bead (Beckman Coulter-A63881) wash was introduced after the MagNA Pure DNA extraction and prior to library preparation for multiplexed runs and DNA was eluted in $15 \mu$ l of nuclease-free water. Modifications for the library preparation were i) $10 \mathrm{ng}$ of input DNA and $2.5 \mu \mathrm{l}$ of FRM were used for the tagmentation/fragmentation reaction and nuclease-free water was used to make the volume up to $10 \mu \mathrm{l}$, ii) for the PCR reaction, 25 cycles were used and the reaction volume was doubled. All samples run using the Pilot method used a 6 min extension time, whereas the Optimised method used a reduced 
extension time of 4 min. When multiplexing, PCR products were pooled together in equal concentrations, then subjected to a 0.6x AMPure XP bead wash and eluted in $14 \mu$ of the buffer recommended in the manufacturer's instructions $(10 \mu \mathrm{L} 50 \mathrm{mM} \mathrm{NaCl}, 10 \mathrm{mM}$ Tris. $\mathrm{HCl}$ pH8.0). Sequencing was performed on the MinION platform using R9.4, R9.5 or R9.4.1 flow cells. The library (50-300 fmol) was loaded onto the flow cell according to the manufacturer's instructions. ONT MinKNOW software (versions 1.4-1.13.1) was used to collect raw sequencing data and ONT Albacore (versions 1.2.2-2.1.10) was used for local base-calling of the raw data after sequencing runs were completed. The MinION was run for up to 48 hours with WIMP/ARMA analysis performed on the first six folders ( 24,000 reads) for Pilot method samples and the first two hours of data for all Optimised method samples.

\section{Quantitative PCR (qPCR) assays}

Probe or SYBR Green based qPCR was performed on samples to detect and quantify human DNA, DNA targets for specific pathogens (E. coli, $H$. influenzae, K. pneumoniae, $P$. aeruginosa, S. aureus, Stenotrophomonas maltophilia and S. pneumoniae) and the bacterial 16S rRNA V3-V4 gene fragment. All qPCR assays were performed on a Light Cycler® 480 Instrument (Roche). Details of primer sequences and targets can be found in Supplementary Table 8 (oligonucleotides were supplied by Sigma or ThermoFisher Scientific).

For all probe-based qPCR reactions, the master mix consisted of $10 \mu \mathrm{l}$ LightCycler 480 probe master (2X), $0.5 \mu \mathrm{l}$ each of reverse and forward primer (final conc. $0.25 \mu \mathrm{M}$ ) and $0.4 \mu \mathrm{l}$ probe (final conc. $0.2 \mu \mathrm{M}$ ). For all SYBR-Green-based qPCR reactions, the master mix consisted of $10 \mu$ LightCycler 480 SYBR Green I master $(2 x)$ and $1 \mu$ l of each forward and reverse primer (final conc. $0.5 \mu \mathrm{M}$ ). To the PCR mix, $2 \mu$ l of DNA template and nuclease-free water to a total volume of $20 \mu \mathrm{l}$ were added. The $\mathrm{qPCR}$ conditions were: pre-incubation at $95^{\circ} \mathrm{C}$ for $5 \mathrm{~min}$, amplification for 40 cycles at $95^{\circ} \mathrm{C}$ for $30 \mathrm{sec}, 55^{\circ} \mathrm{C}$ for $30 \mathrm{sec}$ and $72^{\circ} \mathrm{C}$ for $30 \mathrm{sec}$, with a final extension at $72^{\circ} \mathrm{C}$ for $5 \mathrm{~min}$. Melt curves analysis was performed at $95^{\circ} \mathrm{C}$ for $5 \mathrm{sec}, 65^{\circ} \mathrm{C}$ for 
$1 \mathrm{~min}$, ramping to $95^{\circ} \mathrm{C}$ at $0.03^{\circ} \mathrm{C} / \mathrm{s}$ in continuous acquisition mode, followed by cooling to $37^{\circ} \mathrm{C}$.

\section{Example Limit of detection}

The limit of detection (LoD) of the Optimised method for the detection of one Gram-positive and one Gram-negatie bacteria in sputum was determined using serial dilutions (10 - $10^{5}$ cfu/ml) of cultured E. coli (H141480453) and S. aureus (NCTC 6571). Serial dilutions were made in sterile PBS and plated in triplicate on LB agar to determine colony forming units (CFU) per ml. The same dilutions were used to spike an NRF sputum sample for LoD experiments. Detection and quantification of bacterial DNA was performed using probebased qPCR assays and MinION sequencing.

\section{Mock community experiments}

Clinical isolates from respiratory samples were used to generate a mock community consisting of S. pneumoniae, K. pneumoniae, H. influenzae, S. maltophilia and P. aeruginosa. E. coli and S. aureus strains were also included (H141480453 and NCTC 6571 respectively). Pathogens (E. coli and S. aureus in $10 \mathrm{ml}$ Luria-Broth and K. pneumoniae, P. aeruginosa and S. maltophilia in $10 \mathrm{ml}$ Tryptic Soy Broth (TSB)) were cultured overnight at $37^{\circ} \mathrm{C}$ with shaking at 180 RPM. H. influenzae (in $10 \mathrm{ml} \mathrm{TSB}$ ) and S. pneumoniae (in $10 \mathrm{ml}$ Brain Heart Infusion Broth) were cultured statically at $37^{\circ} \mathrm{C}$ with $5 \% \mathrm{CO}_{2}$ in an aerobic incubator. Cultured pathogens were then spiked into an NRF sample $\left(\sim 10^{8} \mathrm{cfu} / \mathrm{ml}\right.$ per pathogen). The spiked samples were then tested in triplicate with the Optimised method, to determine if saponin depletion resulted in any inadvertent lysis of pathogens and loss of their DNA. All spiked samples were processed alongside undepleted controls. Probe or SYBR Green-based qPCR assays were used to determine the relative quantity of each spiked pathogen in depleted and undepleted spiked sputum samples. 


\section{Pathogen identification and antibiotic resistance gene detection}

The EPI2ME Antimicrobial Resistance pipeline (ONT, versions 2.47.537208- 2.52.1202033) was used for initial analysis of MinION data for the identification of bacteria present in the sample and any associated antimicrobial resistance genes. Within this pipeline, WIMP (What's in my Pot - which utilises 'Centrifuge' kmer-based read identification ${ }^{50}$ ) was used for respiratory pathogen identification and ARMA (Antimicrobial Resistance Mapping Application -which utilised the CARD database ${ }^{51}$ ) for antibiotic resistance gene detection. Potential pathogen(s) were reported if the number of reads accounted for $\geq 1 \%$ of microbial reads and with a WIMP alignment score $\geq 20$. Antibiotic resistance genes were reported if $>1$ gene alignment was present using the 'clinically relevant' parameter within ARMA. This currently only reports resistance genes, acquired and chromosomal, but does not report resistance mutations/SNPs.

\section{Bacterial genome assembly}

Genome assembly was performed first using Fast5-to-Fastq to remove reads shorter than 2000 bp and with a mean quality score lower than seven (https://github.com/rrwick/Fast5-toFastq). Porechop was used to remove sequencing adapters in the middle or the ends of each read, and re-identification of barcodes was carried out for each multiplexed sample (v0.2.3) (https://github.com/rrwick/Porechop). Filtered reads were aligned to a reference genome (chosen based on WIMP classification of pathogen reads) using Minimap2 with default parameters for ONT long-read data (v2.6-2.10) ${ }^{52}$. Finally, Canu was used to assemble mapped reads into contigs using this long-read sequence correction and assembly tool (v1.6) ${ }^{53,54}$. BLAST Ring Image Generator (BRIG) was used for BLAST comparisons of the genome assemblies generated ${ }^{55}$.

\section{Human DNA removal}

Human DNA reads were removed from basecalled FASTQ files using Minimap2 to align to the human hg38 genome (GCA_000001405.15 "soft-masked" assembly) prior to Epi2ME 
analysis. Only unassigned reads were exported to a bam file using Samtools (-f 4 parameter). Non-human reads were converted back to FASTQ format using bam2fastx. These FASTQ files were processed for pathogen identification using WIMP and antibiotic resistance gene detection with ARMA. Further downstream analysis for genome coverage was performed using Minimap2 with default parameters for long-read data (-a -x map-ont) and visualised using qualimap. All clinical sample sequence data and assemblies are available at figshare with human DNA reads removed: pilot method data: https://doi.org/10.6084/m9.figshare.6825410.v1 limit of detection: https://doi.org/10.6084/m9.figshare.6825389.v1 refined method data: https://doi.org/10.6084/m9.figshare.6825470.v1 bacterial genome assemblies: https://doi.org/10.6084/m9.figshare.6825323.v1) .

\section{Acknowledgements}

This study was supported by the UK Antimicrobial Resistance Cross Council Initiative (JOG, GK - MR/N013956/1), Rosetrees Trust (JOG - A749), NIHR INHALE study (JOG, HR, DL, RB - RP-PG-0514-20018), the University of East Anglia (JOG, TC) and Oxford Nanopore Technologies (JOG, TC, DT). Part of the bioinformatics analysis was run on CLIMBcomputing servers, an infrastructure supported by a grant from the UK Medical Research Council (MR/L015080/1). 


\section{Figure legends}

Figure 1: Schematic representation of the metagenomic pipeline with a turnaround time of approx. six hours (refined) and approx. eight hours (pilot) from sample collection to sample result.

Figure 2: Bacterial genome assembly, genome coverage and antibiotic gene detection with depleted versus undepleted samples.

A: MRSA after 48 hours of sequencing.

B: E. coli after 48 hours of sequencing.

C: MRSA genome coverage of depleted versus undepleted during two hours of sequencing.

D: mecA gene alignment of depleted versus undepleted during two hours of sequencing.

E: E. coli genome coverage of depleted versus undepleted during two hours of sequencing.

F: bla TEM, sul1 and dfrA17 gene alignment of depleted versuss undepleted during two hours of sequencing.

\section{Tables}

Table 1: Pilot metagenomic pipeline output compared to routine microbiology culture results.

Table 2: Human and bacterial DNA qPCR results for sputum samples infected by Gramnegative and Gram-positive bacteria with and without host nucleic acid depletion

Table 3: Optimised metagenomic pipeline output compared to routine microbiology culture results

Table 4: Resistance genes found by ARMA in relation to pathogens grown 
Host DNA depletion

Centrifuge samples $(400 \mu \mathrm{l})$ at $8,000 \times \mathrm{xg}$ for $5 \mathrm{~min}$ Resuspend pellet in $250 \mu \mathrm{lPBS}$

\section{Pilot}

Add saponin at $2.5 \%$ final con

$\checkmark$

Incubate at room temp for $10 \mathrm{~min}$

Add $350 \mu \mathrm{l} \mathrm{H}_{2} \mathrm{O}$ and incubate for $30 \mathrm{~s}$ Add $12 \mu \mathrm{l} \mathrm{NaCl}(5 \mathrm{M})$

$\checkmark$

Centrifuge at $6,000 \times \mathrm{xg}$ for $5 \mathrm{~min}$

Resuspend pellet in $100 \mu \mathrm{l}$ PBS

Add $100 \mu \mathrm{l} \mathrm{HL-SAN}$ buffer (5.5 $\mathrm{M} \mathrm{NaCl}, 100 \mathrm{mM} \mathrm{MgCl}_{2}$ )

Add $5 \mu \mathrm{LLL}$-SAN and

incubate for $15 \mathrm{~min}$

at $37^{\circ} \mathrm{C}$ with shaking

Add $2 \mu \mathrm{l} \mathrm{HL-SAN}$ and

incubate for $15 \mathrm{~min}$

at $37^{\circ} \mathrm{C}$ with shaking

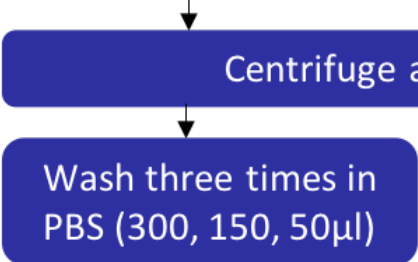

\section{Refined}

Add saponin at $2.2 \%$

final con $^{c}$ ul HL-SAN and

incubate for $15 \mathrm{~min}$

at $37^{\circ} \mathrm{C}$ with shaking

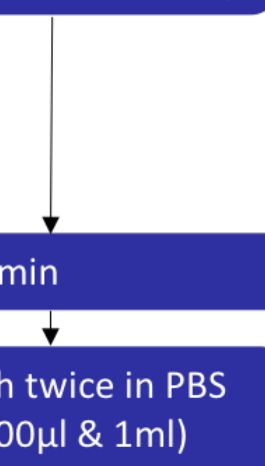

DNA extraction

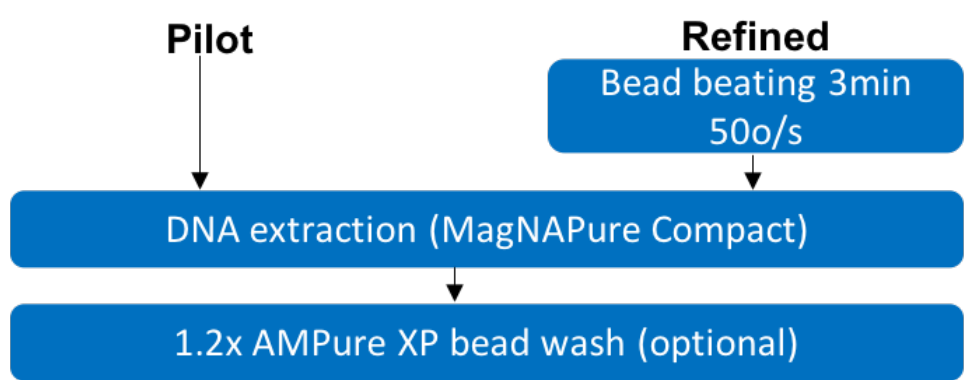

Metagenomic Sequencing

Rapid PCR barcoding library preparation (latest version: SQK-RPB004)

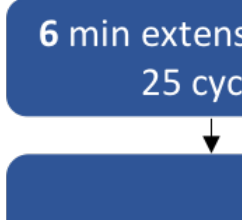

Sequencing with MinION (R9.4/9.5/9.4.1 flowcells) $\checkmark$

Real-time data analysis with WIMP and ARMA 


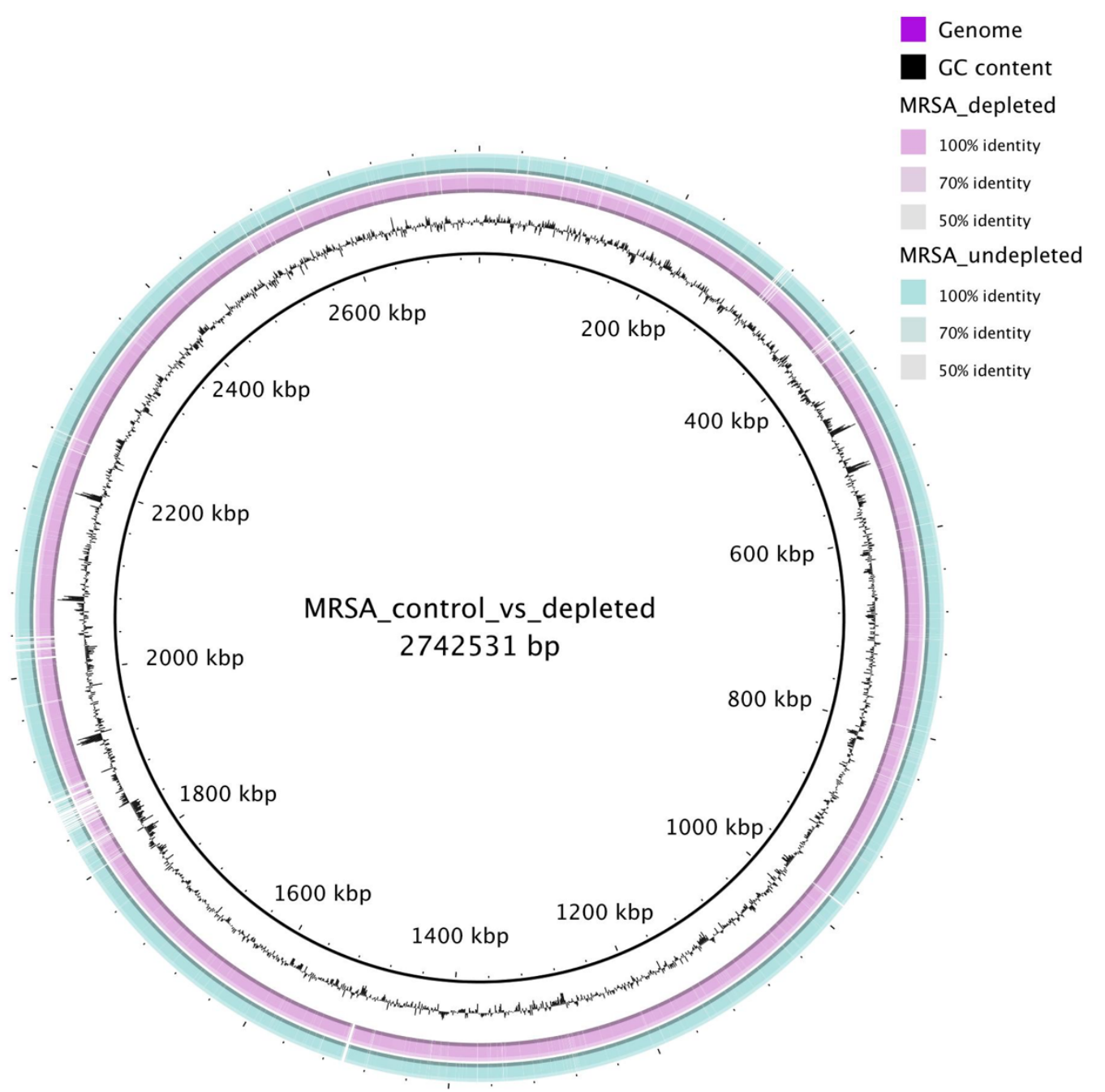




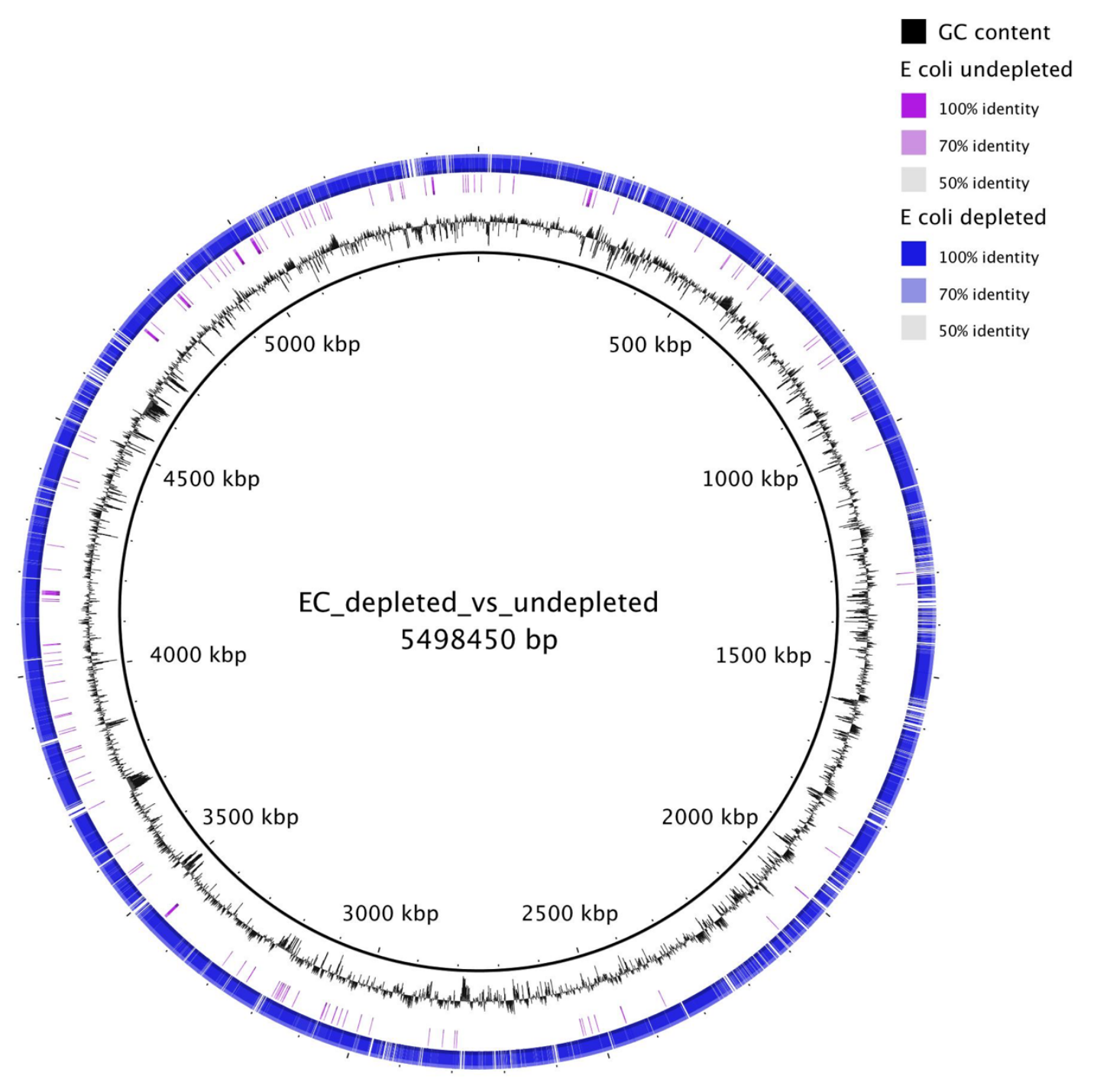




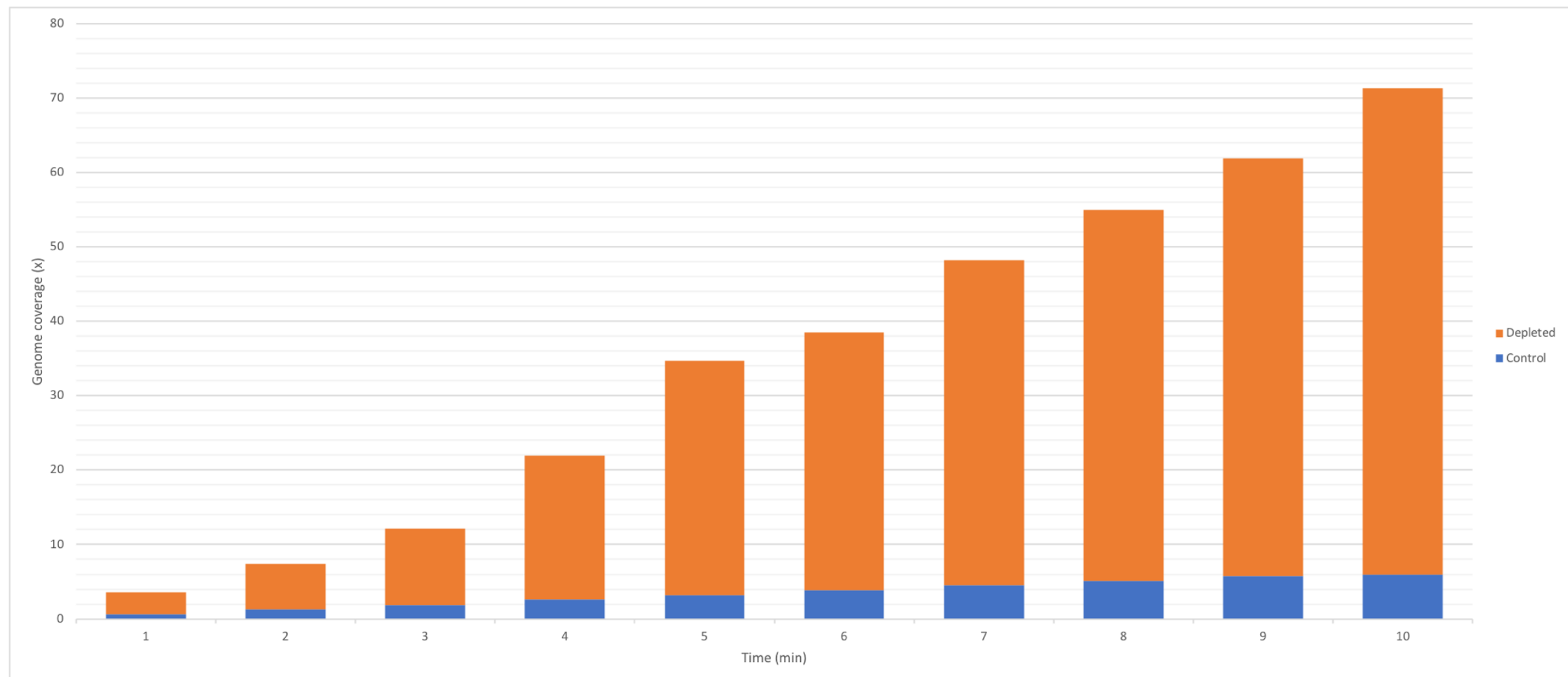




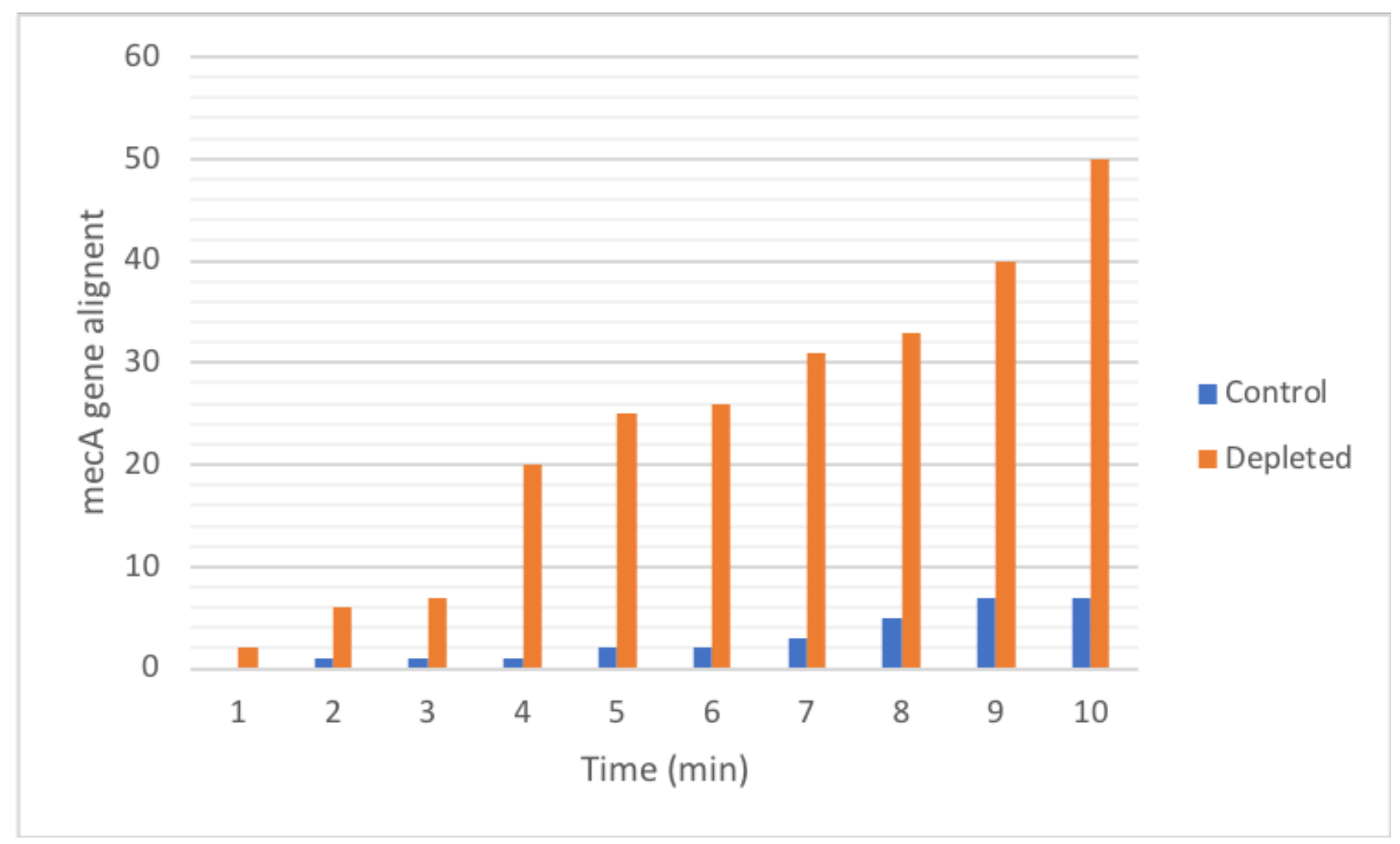




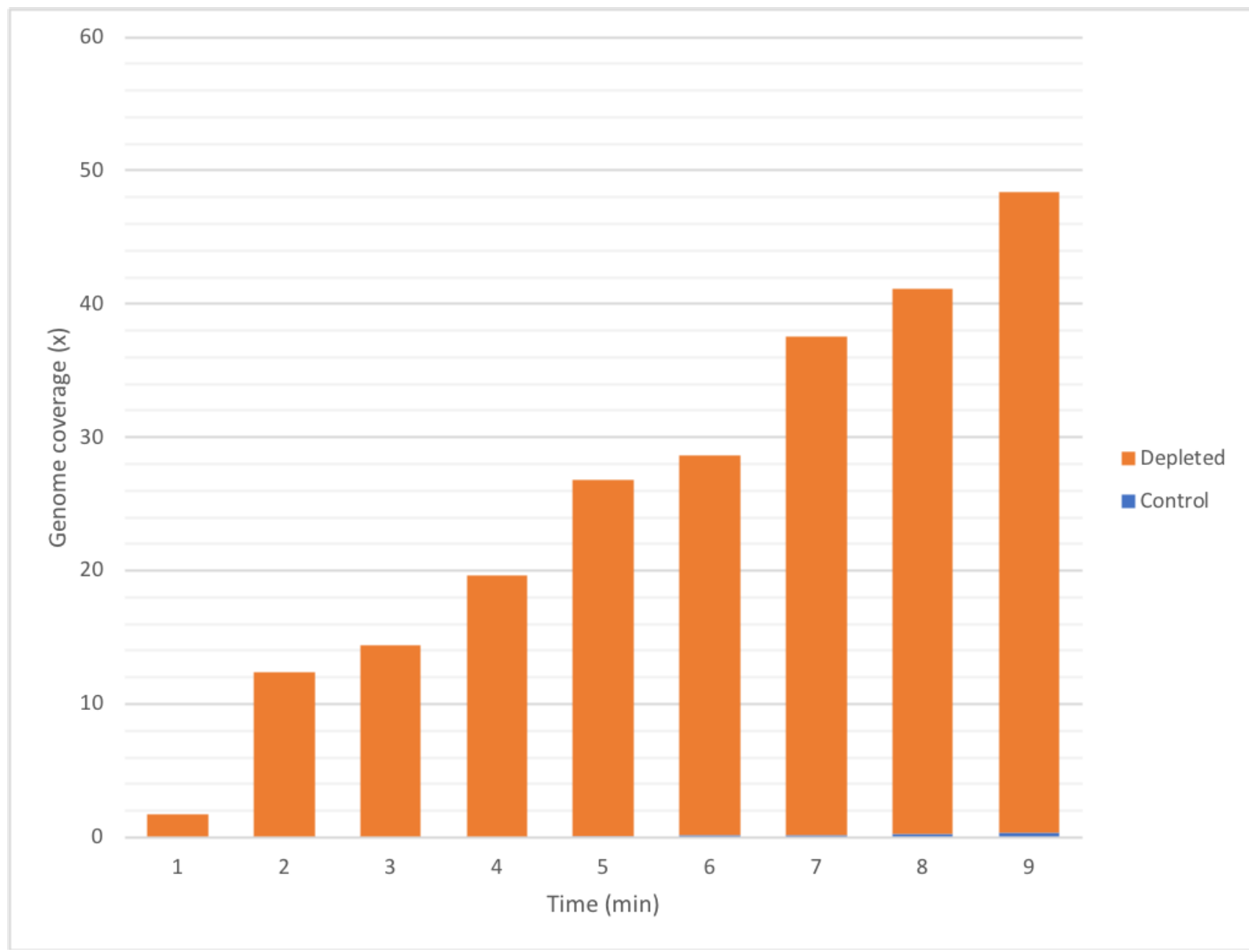




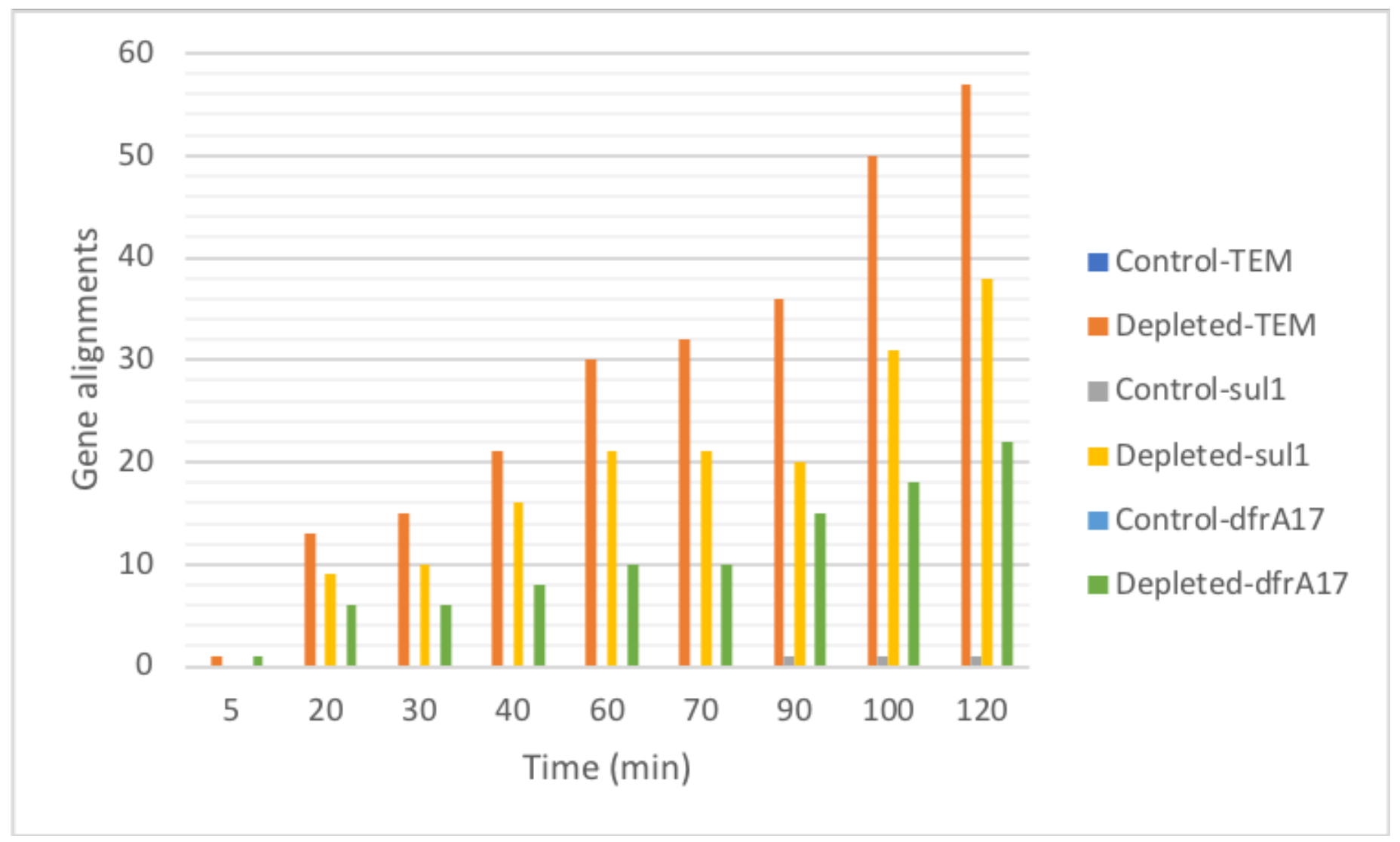


Table 1. Pilot metagenomic pipeline output compared to routine microbiology culture results.

\begin{tabular}{|c|c|c|c|c|}
\hline Pathogen & \multirow{2}{*}{$\begin{array}{c}\text { Culture } \\
\text { positive }\end{array}$} & \multicolumn{3}{|c|}{ Metagenomics } \\
\cline { 3 - 5 } & & Detected & $\begin{array}{c}\text { Missed } \\
\text { detection }\end{array}$ & $\begin{array}{c}\text { Additional } \\
\text { detection }\end{array}$ \\
\hline Haemophilus influenzae & 10 & 9 & 1 & 2 \\
\hline Staphylococcus aureus & 8 & 7 & 1 & 0 \\
\hline Coliform* & 6 & $6^{* *}$ & 0 & 0 \\
\hline Streptococcus pneumoniae & 6 & 5 & 1 & $1\left(1^{* * *}\right)$ \\
\hline Klebsiella pneumoniae & 3 & 3 & 0 & 1 \\
\hline Pseudomonas aeruginosa & 3 & 3 & 0 & 0 \\
\hline Enterobacter aerogenes & 1 & 1 & 0 & 0 \\
\hline Enterobacter cloacae complex & 1 & 1 & 0 & 0 \\
\hline Escherichia coli & 1 & 1 & 0 & 1 \\
\hline Moraxella catarrhalis & 1 & 1 & 0 & 2 \\
\hline None (NRF/NSG) & 0 & 0 & 0 & 1 \\
\hline
\end{tabular}

${ }^{*}$ Coliform not further identified by culture ${ }^{* *} 2 \times$ Escherichia coli, Klebsiella oxytoca, Klebsiella pneumoniae, Proteus mirabilis, Serratia marcescens ${ }^{* * *}$ Additional detection in NRF/NSG samples 
Table 2. Human and bacterial DNA qPCR results for sputum samples infected by Gram-negative and Gram-positive bacteria with and without host nucleic acid depletion

\begin{tabular}{|c|c|c|c|c|c|c|c|}
\hline Sample & $\begin{array}{c}\text { Sample } \\
\text { type }\end{array}$ & $\begin{array}{c}\text { Organism cultured by } \\
\text { microbiology } \\
\text { (Organism identified from } \\
\text { metagenomic pipeline) }\end{array}$ & $\begin{array}{l}\text { Sample } \\
\text { treatment }\end{array}$ & $\begin{array}{l}\text { Human qPCR } \\
\text { assay }(\mathrm{Cq})\end{array}$ & $\begin{array}{l}\text { Human } \\
\text { DNA } \\
\text { depletion } \\
(\Delta \mathrm{Cq})\end{array}$ & $\begin{array}{c}\text { 16S rRNA } \\
\text { gene V3-V4 } \\
\text { fragment } \\
\text { qPCR assay } \\
\text { (Cq) }\end{array}$ & $\begin{array}{c}\text { Bacterial } \\
\text { gain/loss to } \\
\text { standard } \\
\text { depletion } \\
(\Delta \mathrm{Cq})\end{array}$ \\
\hline \multirow[t]{2}{*}{ S1 } & \multirow[t]{2}{*}{ ETA } & \multirow{2}{*}{$\begin{array}{l}\text { E. coli } \\
\text { (E. coli) }\end{array}$} & Undepleted & 22.62 & \multirow{2}{*}{$\begin{array}{l}12.38 \\
\left(\sim 10^{4}\right)\end{array}$} & 15.60 & \multirow[t]{2}{*}{0.13} \\
\hline & & & Depleted & 35.00 & & 15.73 & \\
\hline \multirow[t]{2}{*}{ S2 } & \multirow[t]{2}{*}{ Sputum } & \multirow{2}{*}{$\begin{array}{l}\text { K. pneumoniae } \\
\text { (K. pneumoniae) }\end{array}$} & Undepleted & 23.73 & \multirow{2}{*}{$\begin{array}{c}9.99 \\
\left(\sim 10^{3}\right)\end{array}$} & 15.63 & \multirow[t]{2}{*}{0.02} \\
\hline & & & Depleted & 33.71 & & 15.65 & \\
\hline \multirow[t]{2}{*}{ S3 } & \multirow[t]{2}{*}{ Sputum } & \multirow{2}{*}{$\begin{array}{l}P . \text { aeruginosa } \\
\text { (P. aeruginosa) }\end{array}$} & Undepleted & 23.05 & \multirow{2}{*}{$\begin{array}{c}9.29 \\
\left(\sim 10^{3}\right)\end{array}$} & 15.46 & \multirow[t]{2}{*}{1.48} \\
\hline & & & Depleted & 32.34 & & 13.98 & \\
\hline \multirow[t]{2}{*}{ S4 } & \multirow{2}{*}{ Sputum } & \multirow{2}{*}{$\begin{array}{l}\text { S. marscens } \\
\text { (S. marscens) }\end{array}$} & Undepleted & 26.34 & \multirow{2}{*}{$\begin{array}{c}9.93 \\
\left(\sim 10^{3}\right)\end{array}$} & 16.96 & \multirow[t]{2}{*}{0.52} \\
\hline & & & Depleted & 36.27 & & 17.48 & \\
\hline \multirow[t]{2}{*}{ S5 } & \multirow[t]{2}{*}{ Sputum } & \multirow{2}{*}{$\begin{array}{c}\text { K. oxytoca } \\
\text { (K. oxytoca \& K. pneumoniae) }\end{array}$} & Undepleted & 22.96 & \multirow{2}{*}{$\begin{array}{c}8.58 \\
\left(\sim 10^{3}\right) \\
\end{array}$} & 12.67 & \multirow[t]{2}{*}{0.64} \\
\hline & & & Depleted & 31.54 & & 12.03 & \\
\hline \multirow[t]{2}{*}{ S6 } & \multirow[t]{2}{*}{ Sputum } & \multirow{2}{*}{$\begin{array}{l}\text { S. aureus } \\
\text { (S. aureus) }\end{array}$} & Undepleted & 22.31 & \multirow{2}{*}{$\begin{array}{c}9.41 \\
\left(\sim 10^{3}\right) \\
\end{array}$} & 19.11 & \multirow[t]{2}{*}{1.57} \\
\hline & & & Depleted & 31.72 & & 17.54 & \\
\hline \multirow[t]{2}{*}{ S7 } & \multirow[t]{2}{*}{ Sputum } & H. influenzae & Undepleted & 25.47 & 9.53 & 21.44 & 0.43 \\
\hline & & (H. influenzae \& $P$. aeruginosa) & Depleted & 35.00 & $\left(\sim 10^{3}\right)$ & 21.87 & \\
\hline S8 & Sputum & M. catarrhalis & Undepleted & 22.72 & 9.17 & 16.9 & 0.66 \\
\hline & & (M. catarrhalis \& S. pneumoniae) & Depleted & 31.89 & $\left(\sim 10^{3}\right)$ & 17.56 & \\
\hline S9 & Sputum & $P$. aeruginosa \& E. coli & Undepleted & 23.89 & 11.11 & 19.58 & 3.26 \\
\hline & & (E. coli) & Depleted & 35 & $\left(\sim 10^{4}\right)$ & 22.84 & \\
\hline S10 & Sputum & H. influenzae & Undepleted & 23.46 & 8.6 & 14.12 & 2.39 \\
\hline & & (H. influenzae \& S. pneumoniae) & Depleted & 32.06 & $\left(\sim 10^{3}\right)$ & 16.51 & \\
\hline S11 & Sputum & NRF & Undepleted & 25.77 & 9.23 & 17.96 & 1.92 \\
\hline & & (S. pneumoniae) & Depleted & 35.00 & $\left(\sim 10^{3}\right)$ & 19.88 & \\
\hline S12 & Sputum & NRF & Undepleted & 22.5 & 8.92 & 17.61 & 0.05 \\
\hline & & (H. influenzae \& M. catarrhalis) & Depleted & 31.42 & $\left(\sim 10^{3}\right)$ & 17.56 & \\
\hline S13 & Sputum & S. marscens & Undepleted & 22.48 & 7.11 & 12.77 & 0.79 \\
\hline & & (S. marscens) & Depleted & 29.59 & $\left(\sim 10^{2}\right)$ & 11.98 & \\
\hline
\end{tabular}




\begin{tabular}{|c|c|c|c|c|c|c|c|}
\hline \multirow[t]{2}{*}{ S14 } & \multirow[t]{2}{*}{ Sputum } & \multirow{2}{*}{$\begin{array}{c}\text { S. aureus } \\
\text { (S. aureus \& M. catarrhalis) }\end{array}$} & Undepleted & 23.17 & \multirow{2}{*}{$\begin{array}{c}7.68 \\
\left(\sim 10^{2}\right) \\
\end{array}$} & 13.83 & \multirow[t]{2}{*}{0.96} \\
\hline & & & Depleted & 30.85 & & 14.79 & \\
\hline \multirow[t]{2}{*}{ S15 } & \multirow[t]{2}{*}{ Sputum } & \multirow{2}{*}{$\begin{array}{c}\text { S. aureus } \\
\text { (S. aureus \& S. pneumoniae) }\end{array}$} & Undepleted & 22.66 & \multirow{2}{*}{$\begin{array}{c}8.47 \\
\left(\sim 10^{3}\right)\end{array}$} & 18.73 & \multirow[t]{2}{*}{0.08} \\
\hline & & & Depleted & 31.13 & & 18.65 & \\
\hline \multirow[t]{2}{*}{ S16 } & \multirow[t]{2}{*}{ Sputum } & \multirow{2}{*}{$\begin{array}{c}\text { MRSA } \\
\text { (MRSA) }\end{array}$} & Undepleted & 25.51 & \multirow{2}{*}{$\begin{array}{c}6.43 \\
\left(\sim 10^{2}\right)\end{array}$} & 15.32 & \multirow[t]{2}{*}{0.24} \\
\hline & & & Depleted & 31.94 & & 15.56 & \\
\hline \multirow[t]{2}{*}{ S17 } & \multirow[t]{2}{*}{ Sputum } & \multirow{2}{*}{$\begin{array}{l}\text { NRF } \\
\text { (None) }\end{array}$} & Undepleted & 23.51 & \multirow{2}{*}{$\begin{array}{c}9.64 \\
\left(\sim 10^{3}\right)\end{array}$} & 19.55 & \multirow[t]{2}{*}{1.17} \\
\hline & & & Depleted & 33.15 & & 20.72 & \\
\hline \multirow[t]{2}{*}{ S18 } & \multirow[t]{2}{*}{ Sputum } & \multirow{2}{*}{$\begin{array}{l}\text { H. influenzae } \\
\text { (H. influenzae) }\end{array}$} & Undepleted & 27.14 & \multirow{2}{*}{$\begin{array}{c}7.86 \\
\left(\sim 10^{2}\right) \\
\end{array}$} & 12.89 & \multirow[t]{2}{*}{2.21} \\
\hline & & & Depleted & 35.00 & & 15.10 & \\
\hline \multirow[t]{2}{*}{ S19 } & \multirow[t]{2}{*}{ Sputum } & \multirow{2}{*}{$\begin{array}{c}\text { NRF } \\
\text { (None) }\end{array}$} & Undepleted & 22.63 & 11.18 & 19.69 & 0.69 \\
\hline & & & Depleted & 33.81 & $\left(\sim 10^{3}\right)$ & 19.00 & \\
\hline S20 & Sputum & H. influenzae & Undepleted & 22.44 & 10.03 & 14.99 & 1.19 \\
\hline & & (H. influenzae) & Depleted & 32.47 & $\left(\sim 10^{3}\right)$ & 16.18 & \\
\hline S21 & Sputum & NRF & Undepleted & 24.58 & 10.42 & 16.60 & 0.82 \\
\hline & & (H. influenzae \& S. pneumoniae) & Depleted & 35.00 & $\left(\sim 10^{3}\right)$ & 17.42 & \\
\hline S22 & Sputum & NRF & Undepleted & 22.71 & 9.22 & 14.62 & 0.39 \\
\hline & & (None) & Depleted & 31.93 & $\left(\sim 10^{3}\right)$ & 15.01 & \\
\hline S23 & Sputum & H. influenzae & Undepleted & 24.82 & 10.18 & 16.80 & 1.84 \\
\hline & & (H. influenzae) & Depleted & 35.00 & $\left(\sim 10^{3}\right)$ & 18.64 & \\
\hline S24 & Sputum & H. influenzae & Undepleted & 22.24 & 10.17 & 15.70 & 1.63 \\
\hline & & (H. influenzae) & Depleted & 32.41 & $\left(\sim 10^{3}\right)$ & 17.33 & \\
\hline S25 & Sputum & H. influenzae & Undepleted & 25.52 & 6.26 & 16.59 & 2.67 \\
\hline & & (H. influenzae) & Depleted & 31.79 & $\left(\sim 10^{2}\right)$ & 19.26 & \\
\hline S26 & Sputum & M. catarrhalis & Undepleted & 23.47 & 11.53 & 19.26 & 0.74 \\
\hline & & (M. catarrhalis) & Depleted & 35.00 & $\left(\sim 10^{4}\right)$ & 20.00 & \\
\hline S27 & Sputum & H. influenzae \& S. aureus & Undepleted & 32.74 & 2.26 & 23.19 & 7.92 \\
\hline & & (H. influenzae \& S. aureus) & Depleted & 35.00 & $(\sim 5)$ & 15.27 & \\
\hline S28 & Sputum & NRF & Undepleted & 24.46 & 10.54 & 22.28 & 2.80 \\
\hline & & (S. pneumoniae) & Depleted & 35.00 & $\left(\sim 10^{3}\right)$ & 25.08 & \\
\hline S29 & Sputum & P. aeruginosa & Undepleted & 24.05 & 5.11 & 19.81 & 2.04 \\
\hline & & ( $P$. aeruginosa \& S. aureus) & Depleted & 29.13 & $\left(\sim 10^{2}\right)$ & 17.77 & \\
\hline S30 & $\mathrm{BAL}$ & $P$. aeruginosa & Undepleted & 29.93 & 5.07 & 22.68 & 0.00 \\
\hline & & ( $P$. aeruginosa) & Depleted & $>35.00$ & $(\sim 33)$ & 22.68 & \\
\hline
\end{tabular}




\begin{tabular}{|c|c|c|c|c|c|c|c|}
\hline \multirow[t]{2}{*}{ S31 } & \multirow[t]{2}{*}{ Sputum } & \multirow{2}{*}{$\begin{array}{c}\text { NRF } \\
\text { (H. influenzae) }\end{array}$} & Undepleted & 21.57 & \multirow{2}{*}{$\begin{array}{c}8.26 \\
\left(\sim 10^{3}\right) \\
\end{array}$} & 19.79 & \multirow[t]{2}{*}{1.65} \\
\hline & & & Depleted & 29.83 & & 21.44 & \\
\hline \multirow[t]{2}{*}{ S32 } & \multirow[t]{2}{*}{ Sputum } & \multirow{2}{*}{$\begin{array}{c}\text { NSG } \\
(\text { E. coli) }\end{array}$} & Undepleted & 25.56 & \multirow{2}{*}{$\begin{array}{c}8.68 \\
\left(\sim 10^{3}\right)\end{array}$} & 15.98 & \multirow[t]{2}{*}{0.47} \\
\hline & & & Depleted & 34.24 & & 16.45 & \\
\hline \multirow[t]{2}{*}{ S33 } & \multirow[t]{2}{*}{ Sputum } & \multirow{2}{*}{$\begin{array}{c}\text { NRF } \\
\text { (None) }\end{array}$} & Undepleted & 21.73 & \multirow{2}{*}{$\begin{array}{l}10.04 \\
\left(\sim 10^{3}\right)\end{array}$} & 20.69 & \multirow[t]{2}{*}{0.81} \\
\hline & & & Depleted & 31.77 & & 21.50 & \\
\hline \multirow[t]{2}{*}{ S34 } & \multirow[t]{2}{*}{ Sputum } & \multirow{2}{*}{$\begin{array}{c}\text { NSG } \\
\text { (None) }\end{array}$} & Undepleted & 25.17 & \multirow{2}{*}{$\begin{array}{c}5.40 \\
\left(\sim 10^{2}\right)\end{array}$} & 22.92 & \multirow[t]{2}{*}{0.01} \\
\hline & & & Depleted & 30.57 & & 22.93 & \\
\hline \multirow[t]{2}{*}{ S35 } & \multirow[t]{2}{*}{ Sputum } & \multirow{2}{*}{$\begin{array}{c}\text { E. coli } \\
\text { (E. coli) }\end{array}$} & Undepleted & 21.11 & \multirow{2}{*}{$\begin{array}{c}5.18 \\
\left(\sim 10^{2}\right)\end{array}$} & 16.49 & \multirow[t]{2}{*}{0.58} \\
\hline & & & Depleted & 26.29 & & 17.07 & \\
\hline \multirow[t]{2}{*}{ S36 } & \multirow[t]{2}{*}{ Sputum } & \multirow{2}{*}{$\begin{array}{l}\text { H. influenzae } \\
(\text { H. influenzae })\end{array}$} & Undepleted & 22.58 & \multirow{2}{*}{$\begin{array}{c}9.70 \\
\left(\sim 10^{3}\right)\end{array}$} & 16.51 & \multirow[t]{2}{*}{2.00} \\
\hline & & & Depleted & 32.28 & & 18.51 & \\
\hline \multirow[t]{2}{*}{ S37 } & \multirow[t]{2}{*}{ Sputum } & \multirow{2}{*}{$\begin{array}{c}P . \text { aeruginosa } \\
\text { ( } P \text {. aeruginosa) }\end{array}$} & Undepleted & 21.56 & \multirow{2}{*}{$\begin{array}{r}11.69 \\
\left(\sim 10^{4}\right) \\
\end{array}$} & 15.25 & 1.80 \\
\hline & & & Depleted & 33.24 & & 13.45 & \\
\hline S38 & Sputum & S. aureus \& $P$. aeruginosa & Undepleted & 20.76 & 6.87 & 23.83 & 3.17 \\
\hline & & (S. aureus \& $P$. aeruginosa) & Depleted & 27.63 & $\left(\sim 10^{2}\right)$ & 20.66 & \\
\hline S39 & Sputum & H. influenzae & Undepleted & 23.82 & 11.18 & 14.45 & 2.79 \\
\hline & & (H. influenzae \& M. catarrhalis) & Depleted & 35.00 & $\left(\sim 10^{3}\right)$ & 17.24 & \\
\hline $\mathbf{S 4 0}$ & ETA & MRSA & Undepleted & 21.69 & 4.28 & 19.91 & 1.62 \\
\hline & & MRSA & Depleted & 25.97 & $(\sim 19)$ & 18.29 & \\
\hline S41 & Sputum & H. influenzae \& S. aureus & Undepleted & 20.86 & 14.14 & 16.71 & 6.85 \\
\hline & & (H. influenzae \& S. aureus) & Depleted & 35.00 & $\left(\sim 10^{4}\right)$ & 23.56 & \\
\hline
\end{tabular}


Table 3. Optimised metagenomic pipeline output compared to routine microbiology culture results

\begin{tabular}{|c|c|c|c|c|}
\hline Pathogen & \multirow{2}{*}{$\begin{array}{c}\text { Culture } \\
\text { positive }\end{array}$} & \multicolumn{3}{|c|}{ Metagenomics } \\
\cline { 3 - 5 } & & Detected & $\begin{array}{c}\text { Missed } \\
\text { detection }\end{array}$ & $\begin{array}{c}\text { Additional } \\
\text { detection }\end{array}$ \\
\hline Haemophilus influenzae & 10 & 10 & 0 & $4\left(4^{*}\right)$ \\
\hline Staphylococcus aureus & 8 & 8 & 0 & 1 \\
\hline Pseudomonas aeruginosa & 6 & 5 & 1 & 1 \\
\hline Escherichia coli & 3 & 3 & 0 & $1\left(1^{*}\right)$ \\
\hline Moraxella catarrhalis & 2 & 2 & 0 & $3\left(1^{*}\right)$ \\
\hline Serratia marscens & 2 & 2 & 0 & 0 \\
\hline Klebsiella oxytoca & 1 & 1 & 0 & 0 \\
\hline Klebsiella pneumoniae & 1 & 1 & 0 & 1 \\
\hline Streptococcus pneumoniae & 0 & 0 & 0 & $6\left(4^{*}\right)$ \\
\hline None (NRF/NSG) & 0 & 0 & 0 & $10^{* *}$ \\
\hline
\end{tabular}

${ }^{*}$ Additional detection in NRF/NSG samples ${ }^{* *}$ Two additional pathogens detected in three NRF/NSG samples 
Table 4. Resistance genes found by ARMA in relation to pathogens grown: Optimised pipeline (41 samples; 184 genes detected)

\begin{tabular}{|c|c|c|}
\hline ARMA vs. culture result & $\begin{array}{c}\text { No. } \\
\text { instances }\end{array}$ & Principal examples \\
\hline $\begin{array}{l}\text { Gene recorded in a specimen with } \\
\text { no pathogen grown }\end{array}$ & 56 & $\begin{array}{l}\text { Mostly tet, mef mel, bla TEM-4 determinants, likely to } \\
\text { be associated with normal flora }\end{array}$ \\
\hline $\begin{array}{l}\text { Genes unlikely to be from species } \\
\text { grown by the laboratory }\end{array}$ & 51 & $\begin{array}{l}\text { Mostly gram-positive-associated genes when a } \\
\text { gram-negative organism was grown, or vice versa: } \\
\text { commonly including tet }(M) \text { and mefA }\end{array}$ \\
\hline Gene endogenous in species & 24 & $\begin{array}{l}\text { Mostly efflux components; also blaoxA-50, aph(3')- } \\
\text { IIb and catB7 from P. aeruginosa and aac(6')-Ic } \\
\text { from S. marcescens }\end{array}$ \\
\hline $\begin{array}{l}\text { Partial match to observed } \\
\text { resistances }\end{array}$ & 15 & $\begin{array}{l}\text { Instances where blaTEM was found but where } \\
\text { MinION flagged an ESBL-encoding variant, usually } \\
\text { blaTEM-4, but where the phenotype indicated only a } \\
\text { classical penicillinase, without oxyimino- } \\
\text { cephalosporin resistance }\end{array}$ \\
\hline $\begin{array}{l}\text { Possibly present, but relevant drug } \\
\text { not tested by clin lab }\end{array}$ & 15 & $\begin{array}{l}\text { Commonly (i) where tet(C) found but lab tested } \\
\text { doxycycline, which is not a substrate for this pump, } \\
\text { or (ii) where streptomycin, kanamycin and } \\
\text { macrolide determinants were found in gram- } \\
\text { negative bacteria but these drugs were not tested, } \\
\text { as not relevant to therapy. }\end{array}$ \\
\hline $\begin{array}{l}\text { Does not match phenotype of } \\
\text { isolate }\end{array}$ & 11 & $\begin{array}{l}\text { Mostly where bla Tем (as bla } \text { TEM-4) was recorded but } \text { the isolate (commonly } H \text {. influenzae) was } \\
\text { the } \\
\text { susceptible to penicillins as well as } \\
\text { cephalosporins, or where tet(M) was found } \\
\text { together with a tetracycline-susceptible } S \text {. aureus } \\
\text { Variously including mecA in MRSA, blatEM in }\end{array}$ \\
\hline Match to observed $\mathrm{R}$ & 10 & $\begin{array}{l}\text { Enterobacteriaceae and } H \text {. influenzae, also sul1 } \\
\text { and } d f r \text { determinants for } E \text {. coli }\end{array}$ \\
\hline $\begin{array}{l}\text { Unlikely match to observed } \\
\text { phenotype }\end{array}$ & 2 & $\begin{array}{l}P . \text { aeruginosa with bla TEM resistant to } \\
\text { piperacillin/tazobactam and ceftazidime - see text }\end{array}$ \\
\hline Total & 184 & \\
\hline
\end{tabular}




\section{References}

1. Chalmers, J. et al. Community-acquired pneumonia in the United Kingdom: a call to action. Pneumonia 9, 15 (2017).

2. Carroll, K.C. Laboratory Diagnosis of Lower Respiratory Tract Infections: Controversy and Conundrums. Journal of Clinical Microbiology 40, 3115-3120 (2002).

3. Franklin R. Cockerill, III Rapid Detection of Pathogens and Antimicrobial Resistance in Intensive Care Patients Using Nucleic Acid-Based Techniques, Vol. 63. (2003).

4. Kollef, M.H. Microbiological Diagnosis of Ventilator-associated Pneumonia. American Journal of Respiratory and Critical Care Medicine 173, 1182-1184 (2006).

5. Martínez, M., Ruiz, M., Zunino, E., Luchsinger, V. \& Avendano, L. Detection of Mycoplasma pneumoniae in adult community-acquired pneumonia by PCR and serology, Vol. 57. (2009).

6. Moran, G.J., Rothman, R.E. \& Volturo, G.A. Emergency management of communityacquired bacterial pneumonia: What is new since the 2007 Infectious Diseases Society of America/American Thoracic Society guidelines. American Journal of Emergency Medicine 31, 602-612 (2013).

7. Garcin, F. et al. Non-adherence to guidelines: an avoidable cause of failure of empirical antimicrobial therapy in the presence of difficult-to-treat bacteria. Intensive Care Medicine 36, 75-82 (2010).

8. Hayon, J.A.N. et al. Role of Serial Routine Microbiologic Culture Results in the Initial Management of Ventilator-associated Pneumonia. American Journal of Respiratory and Critical Care Medicine 165, 41-46 (2002).

9. Kodani, M. et al. Application of TaqMan Low-Density Arrays for Simultaneous Detection of Multiple Respiratory Pathogens. Journal of Clinical Microbiology 49, 21752182 (2011).

10. Burnham, C.A. \& Carroll, K.C. Diagnosis of Clostridium difficile infection: an ongoing conundrum for clinicians and for clinical laboratories. Clinical microbiology reviews 26, 604-630 (2013).

11. Lees, E.A., Miyajima, F., Pirmohamed, M. \& Carrol, E.D. The role of Clostridium difficile in the paediatric and neonatal gut - a narrative review. European Journal of Clinical Microbiology \& Infectious Diseases 35, 1047-1057 (2016).

12. Cookson, W., J. Cox, M. \& F. Moffatt, M. New opportunities for managing acute and chronic lung infections, Vol. 16. (2017).

13. Davies, S.C. Chapter 1 Chief Medical Officer's summary. Annual Report of the Chief Medical Officer (2016).

14. O'Neill, J. Tackling drug-resistant infections globally: final report and recommendations. . 84 (2016).

15. Fukumoto, H., Sato, Y., Hasegawa, H., Saeki, H. \& Katano, H. in International journal of clinical and experimental pathology, Vol. 8 15479-15488 (2015).

16. Kais, M., Spindler, C., Kalin, M., Örtqvist, A. \& Giske, C.G. Quantitative detection of Streptococcus pneumoniae, Haemophilus influenzae, and Moraxella catarrhalis in lower respiratory tract samples by real-time PCR. Diagnostic Microbiology and Infectious Disease 55, 169-178 (2006).

17. Hassibi, A. et al. Multiplexed identification, quantification and genotyping of infectious agents using a semiconductor biochip. Nature Biotechnology (2018).

18. Bogaerts, P. et al. Analytical validation of a novel high multiplexing real-time PCR array for the identification of key pathogens causative of bacterial ventilator-associated pneumonia and their associated resistance genes, Vol. 68. (2012).

19. Hasan, M.R. et al. Depletion of Human DNA in Spiked Clinical Specimens for Improvement of Sensitivity of Pathogen Detection by Next-Generation Sequencing. Journal of Clinical Microbiology 54, 919-927 (2016).

20. Loman, N.J. et al. Performance comparison of benchtop high-throughput sequencing platforms. Nature Biotechnology 30, 434 (2012). 
21. Faria, N.R. et al. Establishment and cryptic transmission of Zika virus in Brazil and the Americas. Nature 546, 406 (2017).

22. Quick, J. et al. Real-time, portable genome sequencing for Ebola surveillance. Nature 530, 228 (2016).

23. Anson, L.W. et al. DNA extraction from primary liquid blood cultures for bloodstream infection diagnosis using whole genome sequencing. Journal of Medical Microbiology 67, 347-357 (2018).

24. Greninger, A.L. et al. Rapid metagenomic identification of viral pathogens in clinical samples by real-time nanopore sequencing analysis. Genome Medicine 7, 99 (2015).

25. Schmidt, K. et al. Identification of bacterial pathogens and antimicrobial resistance directly from clinical urines by nanopore-based metagenomic sequencing. Journal of Antimicrobial Chemotherapy 72, 104-114 (2017).

26. Pendleton, K.M. et al. Rapid Pathogen Identification in Bacterial Pneumonia Using Real-Time Metagenomics. American Journal of Respiratory and Critical Care Medicine 196, 1610-1612 (2017).

27. Feehery, G.R. et al. A Method for Selectively Enriching Microbial DNA from Contaminating Vertebrate Host DNA. PLOS ONE 8, e76096 (2013).

28. Thoendel, M. et al. Comparison of microbial DNA enrichment tools for metagenomic whole genome sequencing. Journal of Microbiological Methods 127, 141-145 (2016).

29. Mclntosh, J. Emergency Pathology Service. The Lancet 247, 669-670 (1946).

30. Martner, A., Dahlgren, C., Paton, J.C. \& Wold, A.E. Pneumolysin Released during Streptococcus pneumoniae Autolysis Is a Potent Activator of Intracellular Oxygen Radical Production in Neutrophils. Infection and Immunity 76, 4079-4087 (2008).

31. Regev-Yochay, G. et al. Nasopharyngeal Carriage of Streptococcus pneumoniae by Adults and Children in Community and Family Settings. Clinical Infectious Diseases 38, 632-639 (2004).

32. Thapa, S. et al. Burden of bacterial upper respiratory tract pathogens in school children of Nepal. BMJ Open Respiratory Research 4 (2017).

33. Weiser, J.N. The pneumococcus: why a commensal misbehaves. Journal of Molecular Medicine 88, 97-102 (2010).

34. Chen, J.H.K. et al. Use of MALDI Biotyper plus ClinProTools mass spectra analysis for correct identification of \&lt;em\&gt;Streptococcus pneumoniae\&lt;/em\&gt; and \&lt;em\&gt;Streptococcus mitis\&lt;/em\&gt;/\&It;em\&gt;oralis\&lt;/em\&gt. Journal of Clinical Pathology (2015).

35. Kutlu, S.S., Sacar, S., Cevahir, N. \& Turgut, H. Community-acquired Streptococcus mitis meningitis: a case report. International Journal of Infectious Diseases 12, e107e109 (2008).

36. Services, M. UK Standards for Microbiology Investigations. Investigation of bronchoalveolar lavage, sputum and associated specimens. Bacteriology B57, 38 (2018).

37. Eliopoulos, G.M. \& Huovinen, P. Resistance to Trimethoprim-Sulfamethoxazole. Clinical Infectious Diseases 32, 1608-1614 (2001).

38. Enne, V.I., King, A., Livermore, D.M. \& Hall, L.M.C. Sulfonamide Resistance in Haemophilus influenzae Mediated by Acquisition of sul2 or a Short Insertion in Chromosomal folP. Antimicrobial Agents and Chemotherapy 46, 1934-1939 (2002).

39. Ashton, P.M. et al. MinION nanopore sequencing identifies the position and structure of a bacterial antibiotic resistance island. Nature Biotechnology 33, 296 (2014).

40. Orlek, A. et al. Plasmid Classification in an Era of Whole-Genome Sequencing: Application in Studies of Antibiotic Resistance Epidemiology. Frontiers in Microbiology 8 (2017).

41. Xia, Y. et al. MinION Nanopore Sequencing Enables Correlation between Resistome Phenotype and Genotype of Coliform Bacteria in Municipal Sewage. Frontiers in Microbiology 8 (2017).

42. Leggett, R.M. et al. Rapid MinION metagenomic profiling of the preterm infant gut microbiota to aid in pathogen diagnostics. bioRxiv (2017). 
43. Roberts, A.P. \& Mullany, P. Tn916-like genetic elements: a diverse group of modular mobile elements conferring antibiotic resistance. FEMS Microbiology Reviews 35, 856871 (2011).

44. Santoro, F., Vianna, M.E. \& Roberts, A.P. Variation on a theme; an overview of the Tn916/Tn1545 family of mobile genetic elements in the oral and nasopharyngeal streptococci. Frontiers in Microbiology 5 (2014).

45. Tantivitayakul, P., Lapirattanakul, J., Vichayanrat, T. \& Muadchiengka, T. Antibiotic Resistance Patterns and Related Mobile Genetic Elements of Pneumococci and $\beta$ Hemolytic Streptococci in Thai Healthy Children. Indian Journal of Microbiology 56, 417-425 (2016).

46. Deurenberg, R.H. et al. Application of next generation sequencing in clinical microbiology and infection prevention. Journal of Biotechnology 243, 16-24 (2017).

47. Greninger, A.L. et al. Rapid Metagenomic Next-Generation Sequencing during an Investigation of Hospital-Acquired Human Parainfluenza Virus 3 Infections. Journal of Clinical Microbiology 55, 177-182 (2017).

48. Anscombe, C., Misra, R.V. \& Gharbia, S. Whole genome amplification and sequencing of low cell numbers directly from a bacteria spiked blood model. bioRxiv (2018).

49. Ramachandraiah, $\mathrm{H}$. Microfluidic-based isolation of bacteria from whole blood for sepsis diagnostics. (2014).

50. Kim, D., Song, L., Breitwieser, F.P. \& Salzberg, S.L. Centrifuge: rapid and sensitive classification of metagenomic sequences. bioRxiv (2016).

51. Jia, B. et al. CARD 2017: expansion and model-centric curation of the comprehensive antibiotic resistance database. Nucleic Acids Research 45, D566-D573 (2017).

52. Li, H. Minimap2: pairwise alignment for nucleotide sequences. Bioinformatics, bty191bty191 (2018).

53. Koren, S., Walenz, B.P., Berlin, K., Miller, J.R. \& Phillippy, A.M. Canu: scalable and accurate long-read assembly via adaptive k-mer weighting and repeat separation. bioRxiv (2016).

54. Koren, S. et al. Complete assembly of parental haplotypes with trio binning. bioRxiv (2018).

55. Alikhan, N.-F., Petty, N.K., Ben Zakour, N.L. \& Beatson, S.A. BLAST Ring Image Generator (BRIG): simple prokaryote genome comparisons. BMC Genomics 12, 402 (2011).

56. Klindworth, A. et al. Evaluation of general 16S ribosomal RNA gene PCR primers for classical and next-generation sequencing-based diversity studies. Nucleic Acids Research 41, e1-e1 (2013). 